\title{
JERARQUÍA DE LOS TRATADOS DE DERECHOS HUMANOS: ANÁLISIS JURISPRUDENCIAL DESDE EL MÉTODO DE CASOS
}

\author{
Hierarchy of human rights treaty: analysis jurisprudential \\ from the method of cases
}

\author{
M iriam Lorena Henríquez Viñas ${ }^{1-2}$ \\ Profesor Derecho Constitucional \\ de la Pontificia Universidad Católica de Chile. \\ mlhenriq@uc.cl
}

RESUM EN: No existe en la Constitución Política de Chile una norma que establezca cuál es la jerarquía de los tratados en general y sobre derechos humanos en particular. Por lo tanto, debe determinarse tal rango por la vía de la interpretación del artículo 5o inciso segundo de la Carta Fundamental. La mencionada tarea interpretativa le corresponde a todos los órganos del Estado, pero especialmente a los tribunales de justicia. La jurisprudencia nacional ha ido integrando al ordenamiento interno las normas y principios propios del Derecho Internacional de los Derechos Humanos, reconociendo en este último tiempo jerarquía supralegal e incluso constitucional a los tratados de derechos humanos.

PALA BRA S CLAVE: Tratados internacionales. Tratados de derechos humanos. Jerarquía. Jurisprudencia tribunales superiores de justicia.

ABSTRACT: The Political Constitution of the Republic of Chile does not have a rule that establish which the hierarchy of treaties is in general and treaties about Human

1 A bogado, Universidad Nacional del Comahue, Argentina. Magíster en Derecho Público con mención en Derecho Constitucional, Pontificia Universidad Católica de Chile. Doctor en Ciencias Jurídicas, Universidad de Santiago de Compostela, España. Profesor Derecho Constitucional de la Pontificia Universidad Católica de Chile, Universidad Nacional Andrés Bello, Universidad de Las Américas y Universidad Alberto Hurtado. Email mlhenriq@uc.cl Presentado el 13 de agosto de 2008, aprobado el 25 de octubre de 2008.

2 El presente trabajo ha sido realizado en el marco de los Fondos Concursables de Fomento a la Investigación 2007-2008 de la Dirección de Investigación de la Escuela de Derecho de la Universidad Alberto Hurtado. 
Rights in particular. For this reason, it should be determined the range by the interpretation of Article 5.2 of the Fundamental Charter. The task of interpretation is a work for all the organs of State but especially for the courts of justice. The national jurisprudence has been incorporating to the internal legal ordering the rules and principles from the International Human Rights Law, recognizing in the last time hierarchy supralegal and even constitutional to the Human Rights Treaties.

KEY WORDS: Treaties. Treaties of human rights. Hierarchy. Jurisprudence of the top courts of justice.

\section{EL CRITERIO DE LA JERARQUÍA COMO UNA FORMA DE RESOLVER LOS CONFLICTOS NORMATIVOS}

\section{A. Los conflictos normativos}

Los conflictos normativos o antinomias en un ordenamiento jurídico son inevitables por el dinamismo del ordenamiento y la diversidad de poderes normativos que coexisten en los ordenamientos complejos. ${ }^{3}$ En este caso, la solución al problema de las antinomias debe basarse en el estudio de los distintos principios que ordenan el sistema de fuentes y que determinan el Derecho aplicable.

Antes de analizar los distintos principios que permiten solucionar los conflictos normativos, se hace necesario conceptualizar la expresión "conflicto normativo". En este punto hay que entender, siguiendo a Bobbio, que es aquella situación de incompatibilidad que se produce entre dos normas que pertenecen al mismo ordenamiento y tiene el mismo ámbito de validez, en virtud de la cual la aplicación de una de las normas conduce a resultados contrarios a los que se generan con la aplicación de la otra. ${ }^{4}$

Los definidos conflictos normativos se resuelven mediante la aplicación de distintos principios o criterios: jerarquía, competencia, procedimiento, especialidad, cronológico y prevalencia. En cuanto al principio que nos interesa, el de jerarquía normativa, cabe decir que son distintos los criterios utilizad os para determinar cuándo se está ante una relación jerárquica entre normas. ${ }^{5}$ Sin embargo, tales criterios, separada-

\footnotetext{
Balaguer Callejón (1991), p. 141.

Boвbio (1987), pp. 201-202.

5 Algunas de las soluciones que se han propuesto son tales como la aplicabilidad de la norma superior en caso de conflicto, de la capacidad derogatoria, de la referencia del órgano creador de la norma, de la fundamentación material o formal de la validez, de la posibilidad de fiscalización judicial, o el deber de acatamiento de la norma inferior respecto de la norma superior. Así, autores como García de Enterría expresan que la relación jerárquica deviene de la distinta naturaleza del órgano productor de la norma: "La jerarquía de las normas no es nunca una jerarquía de los procedimientos de producción y elaboración de las mismas, sino un reflejo y una consecuencia de la diferente calidad de los sujetos que las producen: el legislador constituyente en su carácter de fundador del sistema; el legislador ordinario, que extrae su legitimidad y su poder del sistema fundado por aquel; el gobierno, órgano subordinado
} 
mente, parecen todos poco satisfactorios. La conjunción de todos ellos puede servir de pauta para identificar el principio de la jerarquía. Es decir debe considerarse tanto:

a. La posición jerárquica del órgano del que la norma procede.

b. La fuerza que desarrolla cada una de las normas, esto es, una norma superior puede derogar a otra sin que la misma pueda derogarla a ella.

c. Las consecuencias que pueden derivar del incumplimiento del deber de obediencia que en la relación jerárquica se manifiesta. Una norma es superior cuando en su nombre se puede otorgar una acción con el fin de declarar la regla contraria ilegítima.

En conclusión de lo dicho, el razonamiento de la aplicación de la norma superior opera con la siguiente lógica: atendiendo que el ordenamiento jurídico es una pluralidad de clases de normas que coexisten, las normas que ostentan un superior rango prevalecen sobre las normas de categoría inferior, que en la medida en que contravengan aquellas son nulas. ${ }^{6}$

\section{B. La Constitución de Chile y el criterio de jerarquía normativa}

La Constitución es la norma fundamental y fundante del ordenamiento jurídico.

La Constitución es norma jurídica y como tal participa de cuantos caracteres materiales y formales se predican de la norma jurídica en general. Sin embargo, no debe perderse de vista que la Constitución no es sólo norma jurídica, sino que además es una norma declarativa de valores. ${ }^{7}$

A su vez, la Constitución es la norma jurídica fundamental o suprema, ya que su contenido constituye el punto de partida para el desarrollo de todo el ordenamiento jurídico del Estado, el cual debe ordenarse e interpretarse de acuerdo con el sentido de la Constitución. El artículo 60 de la Constitución da cuenta de lo expresado: "LoS órganos del Estado deben someter su acción a la Constitución y a las normas dictadas conforme a ella y garantizar el orden institucional de la República. Los preceptos de

al cuerpo representativo ante el que es responsable (...) y las demás autoridades y órganos inferiores, según el orden de su respectiva jerarquía". García de Enterría (1982), p. 135.

Alzaga Villamil, et al. (1997), p. 262.

Tal como lo expresa el Profesor José Luis Cea Egaña: “Es decir, ellas reconocen los bienes jurídico-políticos que representan el ideal de un Derecho superior a la legalidad vigente, mejor que ésta y trascendente a ella". Las consecuencias que se derivan de esta forma de concebir la Constitución son para el mismo autor: la constitucionalización del sistema jurídico completo de cada país; la aplicación del bloque de constitucionalidad, con los principios y normas del Código Político, de las leyes y de los tratados ligados a la Carta Fundamental, como parámetro para efectuar el control de regularidad de la ley; y la comprensión, interpretación y aplicación del Código supremo con criterios, técnicas y objetivos que no siempre coinciden con el método clásico de la hermenéutica jurídica. CEA EgAÑA (63), p. 433. 
esta Constitución obligan tanto a los titulares o integrantes de dichos órganos, como a toda persona, institución o grupo. La infracción de esta norma generará las responsabilidades o sanciones que determine la ley".

Finalmente, la Constitución es la norma fundante del ordenamiento jurídico por cuanto establece la jerarquía de las fuentes del Derecho y regula las formas de producción de las normas jurídicas. Es opinión unánime de la doctrina que una de las tareas esenciales de la Constitución es precisar los órganos competentes para la producción de las normas jurídicas, como las categorías básicas a través de las cuales se manifiesta la voluntad de dichos órganos y las relaciones entre las mismas por razón de jerarquía o de competencia.

La Constitución, en consecuencia, como norma jurídica fundamental y fundante del ordenamiento jurídico, es quien debe decidir la jerarquía que los tratados internacionales, en general y de derechos humanos en particular, tendrán en el ordenamiento interno, pudiendo decidir que tengan jerarquía legal o supralegal, incluso la Constitución podría disponer resignar o compartir su primer escalón jerárquico con aquéllos. ${ }^{8}$ Sin embargo, como se ha señalado, la Constitución Política de la República de Chile no ha establecido expresamente esta cuestión.

\section{La jerarquía de los tratados de derechos humanos}

Tal cual lo exponía Kelsen en su obra Principios de Derecho Internacional Público, la cuestión de la jerarquía entre el derecho nacional y el internacional puede ser decidida solamente sobre la base del derecho nacional correspondiente..$^{9}$ Esto es, sólo la Constitución de cada Estado resuelve el tema de la jerarquía de los tratados internacionales en el ordenamiento jurídico nacional.

Es por esta razón que el Derecho Comparado muestra diversas soluciones, que al solo efecto de su mejor comprensión se pueden agrupar en distintos sistemas: a) los que colocan a los tratados en un mismo plano jerárquico que las leyes internas; b) otros que consideran a los tratados con una jerarquía superior a las leyes; c) aquellos que otorgan rango constitucional a los tratados; d) finalmente los que reconocen un rango supraconstitucional a los tratados internacionales.

\footnotetext{
Señala el constitucionalista Germán Bidart Campos: “La Supremacía significa entonces, que la Constitución es la fuente primaria y fundante del orden jurídico estatal. De modo que al colocar a la Constitución en el vértice de dicho orden, ella es la que dispone cuál es la graduación jerárquica del mismo. Porque como fuente primaria y fundante puede ocurrir que la Constitución resigne o comparta el primer plano, para reconocer en dicho nivel, al derecho internacional, sea general o de derechos humanos $\mathrm{y} / \mathrm{o}$ al derecho de la integración supraestatal y su derivado, el derecho comunitario". BIDART CAMPOS (1997), pp. 333-373.

9 KeLSEN (1965), p. 359.
} 
La Constitución Política de la República de Chile contiene varias disposiciones relativas a los tratados, entre las que cabe consignar los artículos 50 inciso 2ㅇ, 32 № 15, 54 № $1,93 \mathrm{~N}^{\circ \mathrm{s}} 1$ y 3 ; sin embargo ninguna de aquellas explicita la jerarquía de los tratados. ${ }^{10}$ En consecuencia habrá de estar a la interpretación que han realizado los tribunales de justicia sobre el particular.

En este estudio, el examen de dicha Evolución Jurisprudencial se centrará en aquellos fallos referidos a la jerarquía de los tratados de derechos humanos, avanzando en su evolución por cuatro etapas. La primera que se extiende desde la Constitución de 1980 hasta la reforma de 1989, en la que se agrega el inciso segundo al artículo 5o constitucional; la segunda que va desde 1989 hasta 1994, año en que se dictan sendos fallos que reconocen la jerarquía supralegal de los tratados de derechos humanos, casos Lumi Videla y Uribe Tambley-Van Jurick, la tercera etapa desde 1994 hasta 2005, año en que se dicta por la Corte Interamericana de Derechos Humanos el fallo A Imonacid A rellano vs. Chile, que impone a los tribunales de justicia nacionales el control de convencionalidad; finalmente, la cuarta etapa que se extiende desde el año 2005 a la actualidad. ${ }^{11}$

\section{PRIMERA ETAPA DE EVOLUCIÓN JURISPRUDENCIA : 1980-1989}

En este apartado, el examen de la Evolución Jurisprudencial se centrará en aquellos fallos de los tribunales superiores de justicia referidos a los tratados de derechos humanos, que se extiende desde la vigencia de la Constitución de 1980 hasta la reforma constitucional de 1989, en la cual se agregó la parte final al inciso segundo del artículo 5o constitucional.

Antes de iniciar el análisis de esta etapa, cabe señalar brevemente que durante la vigencia de la Constitución de 1925 y hasta la entrada en vigencia de la Constitución de 1980 la mayor parte de los casos fueron resueltos por los tribunales en base a un problema que resultó ser insalvable para quienes demandaron tutela judicial por esos años: el de la falta de publicación de los tratados internacionales. En esta época imperó la tesis que asimila el tratado a la ley, concluyendo que si el tratado no es publicado el mismo no es obligatorio en Chile y en consecuencia no es oponible, siendo los derechos consagrados en él meras expectativas. ${ }^{12}$ Tal fue la situación del Pacto Internacional de Derechos Civiles y Políticos de la ONU de 1976, el que no fue publicado en Chile sino hasta 1989, o sea trece años después de su promulgación y diez años desde que comenzó a tener vigencia internacional. ${ }^{13}$

10 Ver Henriquez Viñas (2007), pp. 313-323.

11 Nota del autor. Este trabajo analiza las sentencias de los tribunales superiores de justicia hasta el 31 de diciembre de 2007.

12 A mayor abundamiento ver Benadava (1992). Además consultar Henríquez Viñas (2003), pp. 47-68.

13 El Pacto Internacional de Derechos Civiles y Políticos de 1966 fue publicado el 29 de abril de 1989 en el Diario Oficial, promulgado por Decreto Supremo № 778 el 30 de noviembre de 1976, entrando en vigencia internacional el 23 de marzo de 1976, de conformidad con el artículo 49 del mismo. 
Entrando ya al análisis de la etapa en cuestión, es necesario aclarar que la versión original del artículo $5^{\circ}$ inciso segundo de la Constitución constaba de una sola oración que decía: "El ejercicio de la soberanía reconoce como limitación el respeto a los derechos esenciales que emanan de la naturaleza humana". La reforma constitucional de 1989 incorporó la segunda oración que agrega: "Es deber de los órganos del Estado respetar y promover tales derechos, garantizados por esta Constitución, así como por los tratados internacionales ratificados por Chile y que se encuentren vigentes". ${ }^{14}$

Como señala Gerardo Bernales, a la época de entrada en vigencia de la Constitución y hasta la reforma de agosto de1989 se encontraban vigentes en Chile 26 tratados relativos a los derechos humanos. ${ }^{15}$ Sin embargo, en esta misma etapa, se consideraban como no vigentes, por falta de publicación, el Pacto de San José de Costa Rica y el Protocolo Facultativo del Pacto Internacional de Derechos Civiles y Políticos. ${ }^{16}$

14 Para una completa explicación sobre los orígenes y razones de la reforma constitucional de 1989 y especialmente en materia de tratados de derechos humanos, ver CUM PLIDO CERECEDA (1991), pp. 195 y SS.

15 Ver Bernales Rojas (2003), pp. 281-327. Los tratados enumerados son: Declaración Universal de los Derechos Humanos, 10/12/48; Declaración A mericana de los Derechos y Deberes del Hombre, aprobada en Bogotá, Colombia, 1948; Pacto Internacional de los Derechos Económicos, Sociales y Culturales, entrada en vigor internacional para Chile el 10/3/72, publicado en el Diario Oficial el 27/5/89; Pacto Internacional de Derechos Civiles y Políticos, entrada en vigor internacional para Chile 10/5/72, publicado en el Diario Oficial 29/4/89; Convención contra la Tortura y otros Tratos o Penas Crueles, Inhumanos o Degradantes, publicado en el Diario Oficial el 26/11/88; Convención Interamericana para Prevenir y Sancionar la Tortura, publicado en el Diario O ficial 26/12/88; Convenio internacional destinado a asegurar una protección eficaz contra el tráfico criminal conocido bajo el nombre de «Trata de Blancas», publicado en el Diario Oficial el 18/6/35; Convención internacional relativa a la represión de la trata de blancas, publicado en el Diario Oficial el 18/6/35; Convención internacional para la represión de la trata de mujeres y niños, publicado en el Diario Oficial el 20/5/30; Convención internacional relativa a la represión de la trata de mujeres mayores, publicado en el Diario Oficial el 15/4/35; Convención sobre condición de los extranjeros, publicado en el Diario Oficial el 14/9/34; Convención sobre el estatuto de los refugiados, publicado en el Diario Oficial el 19/7/72; Protocolo sobre el estatuto de los refugiados, publicado en el Diario Oficial el 20/7/72; Convención sobre nacionalidad de la mujer, publicado en el Diario Oficial el 12/11/34; Convención interamericana sobre concesión de los derechos políticos a la mujer, publicado en el Diario Oficial el 26/5/75; Convención sobre los derechos políticos de la mujer, publicado en el Diario Oficial el 30/9/67; Convención sobre asilo político, publicado en el Diario Oficial el 17/5/35; Protocolo referente a un cierto caso de apatridia, publicado en el Diario Oficial el 16/4/35; Convención internacional sobre la eliminación de todas las formas de discriminación racial, publicado en el Diario Oficial el 12/11/71; Convención relativa a la lucha contra las discriminaciones en la esfera de la enseñanza, publicado en el Diario Oficial el 30/11/71; Convención para la prevención y la sanción del delito de genocidio, publicado en el Diario Oficial el 11/12/53; Convención para la prevención y el castigo contra personas internacionalmente protegidas, inclusive los agentes diplomáticos, publicado en el Diario Oficial el 29/3/77; Convenio para mejorar la suerte de los heridos y los enfermos de las fuerzas armadas en campaña, publicado en el Diario Oficial el 17, 18, 19 y 20/4/51; Convenio para mejorar la suerte de los heridos, enfermos y náufragos de las fuerzas armadas en el mar, publicado en el Diario Oficial el 17/4/51; Convención sobre el tratamiento de los prisioneros de guerra, publicado en el Diario Oficial el 18/4/51; Convención sobre la protección a las personas civiles en tiempos de guerra, publicado en el Diario Oficial el 19 y 20/4/51.

16 La Convención A mericana sobre Derechos Humanos o Pacto de San José de Costa Rica, fue publicado en el Diario Oficial el 5/1/91; y el Protocolo Facultativo del Pacto Internacional de Derechos Civiles y Políticos, publicado en el Diario Oficial el 20/8/92. 
Los casos más importantes en los que los tribunales resolvieron un conflicto normativo en que un tratado era norma aplicable fueron los llamados casos Leopoldo Ortega, Consejero de la Embajada de Alemania y Cónsul de Alemania. El primero de los casos, que se analizará a continuación, dice relación con la aplicación del Pacto de los Derechos Civiles y Políticos. ${ }^{17}$

El llamado caso Leopoldo Ortega, del año 1984, fue resuelto por la Corte de Apelaciones de Santiago y se refirió al problema de la contradicción entre tratado y Constitución y a la no publicación del primero en los siguientes términos: "Que cualesquiera que sean los efectos y alcances del Pacto Internacional de Derechos Civiles y Políticos (...) que ha sido promulgado, pero no publicado, es lo cierto que sus cláusulas y disposiciones no podrían, dentro de un orden de prevalencia razonable y natural, contrariar preceptos constitucionales, ni menos primar sobre estos". ${ }^{18}$

En este caso existía un conflicto entre normas constitucionales y un tratado internacional, puesto que se había decretado la expulsión del territorio nacional, la prohibición de ingresar al mismo y el arresto de los recurrentes en virtud de normas legales y constitucionales, lo que claramente era contrario a lo dispuesto por el Pacto de los Derechos Civiles y Políticos. ${ }^{19}$

La sentencia citada fue acordada con el voto disidente del Ministro Paillas, quien estuvo por acoger el recurso de amparo en virtud del artículo 12 del Pacto, norma citada por el disidente, como también por lo dispuesto en el artículo 19 № 7 a) de la Constitución. El Ministro Paillas entendió que una norma internacional posee requisitos de existencia y validez propios, de modo que señaló: "Que, en consecuencia, los decretos antes mencionados no han podido apartarse de las normas antedichas que han sido reconocidas por la primera autoridad de la Nación, la que dispuso que dicho Pacto se cumpla y se lleve a efecto como Ley de la República, si bien hasta ahora no ha sido publicada". En igual sentido se plasmó el voto disidente del Ministro Paillas en el caso De Negri, dictado por la Corte de A pelaciones de Santiago, de 13 de octubre de 1986, cuya apelación fue confirmada por la Corte Suprema en fallo de 20 de octubre de 1986. ${ }^{20}$

17 Los Casos Consejero de la Embajada de Alemania y Caso Cónsul de Alemania no se analizarán porque si bien tuvieron en cuenta la aplicación de dos tratados internacionales: la Convención de Viena sobre Relaciones Diplomáticas de 1961 y la Convención de Viena sobre Relaciones Consulares, aquellos no versaban sobre derechos humanos.

18 Revista Fallos del Mes, 311 (1986), pp. 588 y ss.

19 Decretos $N^{\text {os }} 4542,4547,4556$ y 4681 ordenados en uso de la facultad que se concedía por el artículo 24 transitorio, letras a) y c) de la Constitución.

20 Gerardo Bernales señala que el voto disidente en comento tiene un triple mérito: “El primero es que hace vinculación directa de un Pacto Internacional con la Constitución; es decir, lo reconoce y ampara en forma directa por vía de aplicación de un derecho protegido internacionalmente a través de la Constitución en su artículo $5^{\circ}$ inciso $2^{\circ}$. El segundo es que no sólo disintió en cuanto a la procedencia del recurso sino que además se pronuncia directamente sobre el fondo del mismo. Y el tercer mérito es que hace una aplicación finalista de la Constitución, por cuanto hace aplicable el Pacto Internacional de Derechos Civiles y Políticos en circunstancias que dicho Pacto no había sido publicado para su entrada en vigor, aludiendo al mandato del Decreto № 778 de 30 de noviembre de 1976, por el cual se dispuso 
En el mismo caso, la Corte Suprema estimó que a los tribunales sólo les corresponde aplicar los tratados vigentes en Chile. Fundamentó para ello que la entrada en vigencia se encuentra reglada por el decreto ley 247 y el mismo exige la publicación: "La materia se encuentra reglada hoy por la concluyente normativa dispuesta por el Decreto Ley No 247 de 31 de diciembre de 1973". A gregó: "Que habiéndose llegado a este punto y encontrándose establecido en autos que ni el decreto promulgador del Pacto que ordenó cumplirlo como Ley de la República, ni el texto del mismo han sido hasta la fecha publicados en el Diario Oficial, es fundado concluir que dicho Pacto carece de fuerza obligatoria en Chile, al igual que, en idéntica situación, carecería de ella una ley promulgada pero no publicada".

Con respecto a la incorporación de los tratados al ordenamiento interno la Corte Suprema aseveró: "Que finalmente, la tesis de la incorporación automática del Pacto a nuestro Derecho interno está desautorizada por lo dispuesto en el artículo 2, párrafo 2 del propio Pacto en cuestión, el cual dispone: "Cada Estado Parte se compromete a adoptar, con arreglo a sus procedimientos constitucionales y a las disposiciones del presente Pacto, las medidas oportunas para dictar las disposiciones legislativas o de otro carácter que fueren necesarias para hacer efectivos los derechos reconocidos en el presente Pacto y que no estuvieren ya garantizados por disposiciones legislativas o de otro carácter". Este precepto torna, pues, incuestionable que los propios Estados Partes del Pacto estuvieron acordes en que sus estipulaciones carecían de virtualidad de reputarse incorporadas automáticamente a su derecho interno. Por el contrario, previnieron que para ello se requería que cada cual adoptara los procedimientos y formalidades prescritos por su propia legislación nacional al efecto".

Como puede observarse en el caso en cuestión, la falta de publicación del tratado fue un obstáculo para el recurrente para demandar ante los tribunales los derechos previstos en aquél. El problema planteado dice relación con la incorporación de los tratados internacionales al ordenamiento interno. En el caso chileno y pese el silencio de la Constitución, se ha concluido que el sistema de recepción del derecho internacional convencional es el de la incorporación, es decir la recepción se produce mediante el cumplimiento de una formalidad determinada, tal como la publicación oficial del tratado, su promulgación y publicación, o su proclamación.

La ausencia de regulación constitucional o legal de esta materia constituye una grave deficiencia, toda vez que, como se ha visto, el silencio puede dar origen a soluciones encontradas en la práctica internacional, en la doctrina y también en la jurisprudencia. En efecto, es evidente que los tribunales de la época otorgaron a la publicación un efecto constitutivo, entendiendo que mediante ella se produce la incorporación de la norma convencional al Derecho chileno. Este razonamiento es cono-

que se cumpla y se lleve a efecto como ley de la República, interpretación que desde la perspectiva del formal resulta forzada, pero que con la perspectiva del tiempo y las circunstancias no lo es tanto, pues en aquella época no estaba en vigencia aún la Constitución". BernALes RojAs (2003), pp. 281-327. 
cido como tesis reduccionista, cuya idea fuerza es que no son necesarias las normas constitucionales sobre promulgación y publicación de tratados internacionales porque se siguen los trámites de la ley al respecto. Las principales consecuencias que atribuye la tesis reduccionista a los tratados que no se publican a nivel interno son la no obligatoriedad e inoponibilidad del tratad o y la consideración de los derechos consagrados en el tratado no publicado como meras expectativas. Las críticas que se han formulado a la postura reduccionista se basan esencialmente en la diferencia entre el tratado y la ley y en la circunstancia que en el Derecho internacional no existe ninguna regla que condicione la vigencia de un tratado a su publicación interna. ${ }^{21-22}$

Como se observa en esta etapa, las sentencias aplicaron a los tratados internacionales las categorías propias del Derecho interno, lo que ciertamente contradice los propios pactos y los artículos 18 y 27 de la Convención de Viena sobre el Derecho de los tratados. Del fallo analizado puede concluirse que en este periodo la Jurisprudencia consideraba que los tratados tenían el mismo valor y jerarquía que la ley. Por otro lado, continuó la concepción imperante bajo la Constitución de 1925, sobre la inaplicabilidad de aquellos pactos que habían sido promulgados pero no publicados, con fundamento nuevamente en la asimilación de los tratados a la ley.

\section{SEGUNDA ETAPA DE EVOLUCIÓN JURISPRUDENCIAL: 1989-1994}

La segunda etapa de Evolución Jurisprudencial se extiende desde 1989 hasta 1994, año en que se dictó el primer fallo que reconoce la jerarquía constitucional de los tratad os de derechos humanos. Las resoluciones judiciales recaídas en esta etapa giraron en torno a tres materias, en las que se evidencia no sólo una referencia a los tratados de derechos humanos y su aplicación, sino especialmente a la jerarquía de estos. Las materias que se comprenden son aquellas relativas a la ley de cheques, deudas previsionales y aplicación del decreto ley de amnistía.

21 Los argumentos han sido claramente expuestos por Precht Pizarro, quien explica: "A nte todo, la primera de estas conclusiones se basa en una posición ampliamente superada por la ciencia jurídica contemporánea, esto es, el dualismo, a saber el que podría existir una vigencia de la norma en el orden internacional y una no vigencia en el orden interno o a los menos la posibilidad de la impermeabilidad absoluta del orden jurídico interno y del orden internacional". Concluye Precht Pizarro: "A mi juicio es necesario señalar que la publicación no es en sí misma condición de validez, ni internacional ni interna del tratado". Precht Pizarro (1996), pp. 146-150.

22 En este sentido, es valiosa la rectificación del Profesor Silva Bascuñán, quien, en el año 1989, consideró que los mismos trámites previstos para la ley debían ser aplicados para los tratados, incluso los de promulgación y publicación. Luego, a partir de 1997, Silva Bascuñán separó los trámites de promulgación y publicación de un tratado respecto de aquellos previstos para las leyes, en el entendido que la asimilación sólo se refiere a los trámites de su aprobación y la promulgación y publicación no lo son, pues son consecuencias de ella. A firma Silva Bascuñán que en la formación y en la sanción el Presidente actúa como colegislador, y en la promulgación lo hace como Jefe del Poder Ejecutivo, en cumplimiento de la ley aprobada y sancionada. SILVA BASCUÑán (1997), p. 123. 


\section{A. Casos sobre ley de cheques}

El artículo 7 № 7 de la Convención A mericana sobre Derechos Humanos prohíbe la prisión por deuda en los términos siguientes: "Nadie será detenido por deudas". A su vez, el Pacto Internacional de Derechos Civiles y Políticos establece en su artículo 11: "Nadie será encarcelado por el sólo hecho de no poder cumplir con una obligación contractual".

A partir del momento que entró en vigor la Convención Americana sobre Derechos Humanos o Pacto de San José de Costa Rica en el ordenamiento jurídico chileno y especialmente a partir de la reforma constitucional de 1989 al artículo 50 inciso segundo de la Constitución, se invocó el artículo 7 № 7 de dicho tratado para solicitar la libertad provisional por el delito de giro doloso de cheques. Los fallos se refirieron principalmente a la compatibilidad entre el artículo 7 № 7 del Pacto San José de Costa Rica con el artículo 44 del D.F.L. № 707 sobre cuentas corrientes bancarias y cheques. ${ }^{23}$ La jurisprudencia ha sido vacilante en declarar la compatibilidad entre ambos, tal como se desprenderá del análisis de los casos siguientes.

La Corte de A pelaciones de Santiago, en un fallo del 5 de febrero de 1991, señaló la incompatibilidad entre el artículo 44 de la Ley sobre Cuentas Corrientes Bancarias y Cheques con el artículo 7 № 7 de la Convención A mericana sobre Derechos Humanos, privilegiando la aplicación del tratado internacional: "Se exime al reo de la caución establecida en el artículo 44o de la Ley sobre Cuentas Corrientes Bancarias y Cheques por considerar que dicho artículo 44 se encuentra en pugna, en la parte que exige la caución de un depósito de dinero por el total de los cheques, intereses y costas, con lo prevenido en el artículo 50 inciso final de la Constitución Política antes citada, en relación con el artículo 7은 7 de la Convención A mericana sobre Derechos Humanos, denominada Pacto San José de Costa Rica, (...) en atención a que la naturaleza de dicha caución y el objetivo primordial que persigue, constituyen un entorpecimiento que hace de la prolongación de la prisión preventiva, más allá de su concesión por la autoridad judicial, una verdadera prisión por deudas". ${ }^{4}$

Días después, el 11 de febrero, nuevamente la Corte de A pelaciones de Santiago en el caso Quinteros Marabolí, con el voto en contra del abogado integrante, reiteró la

23 El artículo 70 del Pacto señala: "Toda persona tiene derecho a la libertad y a la seguridad personales"; en su número 70, prescribe: "Nadie será detenido por deudas. Este principio limita los mandatos de autoridad judicial competente dictados por incumplimiento de deberes alimentarios". A su vez, el artículo 44 del D.F.L. № 707, señala: “Los procesos criminales por los delitos contemplados en los artículos 22 y 43, procederá la excarcelación de acuerdo a las reglas generales. En todo caso se exigirá, además, caución y no se admitirá otra clase que no sea un depósito de dinero de un monto no inferior al importe del cheque, más los intereses y costas que fije prudencial y provisionalmente el tribunal". En el inciso segundo del mismo artículo se señala: "La responsabilidad civil del librador podrá hacerse efectiva sobre dicha caución".

24 Corte de A pelaciones de Santiago. No se consignan (1991). 
incompatibilidad, estableciendo la aplicación del tratado por sobre la ley interna, en los siguientes términos: "Que el artículo 44 de la Ley sobre Cuentas Corrientes Bancarias y Cheques, en la parte que exige la caución de un depósito de dinero por el total de los cheques, intereses y costas, se encuentra en pugna con lo prevenido en el artículo 5o inciso final de la Constitución Política del Estado en relación con el artículo 7 № 7 del tratado internacional denominado San José de Costa Rica promulgado en Chile el 5 de enero de este año, se revoca en lo apelado la resolución de 7 de febrero en curso, escrita a fojas. 92 y se declara que se exime al reo Ernesto Quinteros Marabolí de la aludida caución, por estimar que ella constituye un entorpecimiento que hace de la prisión preventiva, más allá de su concesión por la autoridad judicial, una verdadera prisión por deudas". ${ }^{25}$ Este fallo fue impugnado por la vía del recurso de queja, siendo confirmado por la Corte Suprema de Justicia, en fallo de fecha 18 de abril de 1991.

Cabe decir que la Corte de A pelaciones de Santiago, en sentencia de 12 de abril de 1991 resolvió respecto de la aplicación del artículo 163, letra f) del Código Tributario, norma similar a la del artículo 44 del D.F.L. № 707. ${ }^{26}$ En relación con la misma la Corte de A pelaciones de Santiago, como en los casos anteriores, estimó la incompatibilidad de la caución prevista en dicho artículo con las disposiciones del Pacto de Derechos Civiles y Políticos y el Pacto de San José de Costa Rica: “(..) no está de más hacer constar que en concepto de estos jueces la caución que prescribiría el artículo 163 letra f) del Código Tributario, ha sido derogado por la modificación introducida a los artículos 50 inciso 2 - y 19 № 26 de la Constitución, habida cuenta en el caso de aquel, de lo que preceptúan los artículos 9.1 del Pacto Internacional de Derechos Civiles y Políticos y 7.1 de la Convención A mericana sobre Derechos Humanos, ambas ratificadas por Chile y actualmente vigentes. (...) Por estas consideraciones, se revoca la resolución de 9 de abril (...) dejándose sin efecto la caución que allí se regula". ${ }^{27}$

En el caso A raya Villarroel, el 2 de mayo de 1991, la Corte Suprema confirmó una sentencia de la Corte de A pelaciones de Santiago decidiendo sobre la incompatibilidad entre lo preceptuado en el artículo 44 de la Ley de Cheques y el Pacto de San José de Costa Rica, exigiendo una caución de un monto menor de lo estipulado en esta norma. La Corte Suprema señaló: "Lo resuelto se encuentra además en concordancia con el artículo 7 № 7 de la Convención Americana de Derechos, denominado Pacto de

25 Corte de A pelaciones de Santiago. No se consignan (1991).

26 El artículo 163, letra f) del Código Tributario dispone: "Cuando proceda la excarcelación, el juez fijará el monto de la fianza en una suma no inferior al $30 \%$ de los impuestos evadidos, reajustados en la forma prevista en el artículo 53, y de acuerdo a la estimación que de ellos se haga por el Servicio de Impuestos Internos. La excarcelación se otorgará y la fianza se rendirá de acuerdo a los incisos segundo y tercero del artículo $361^{\circ}$ del Código de Procedimiento Penal, cualquiera que sea la pena asignada al delito. Sin embargo, en los casos a que se refiere el inciso tercero del № 4 del artículo 970, la excarcelación procederá de acuerdo con las reglas generales, pero se exigirá, además, caución y no se admitirá otra que no sea un depósito de dinero de un monto no inferior al de la devolución indebidamente obtenida, según los antecedentes que presente el Servicio de Impuestos Internos. Sobre este monto, el Tribunal fijará los reajustes e intereses que procedan".

27 Corte de Apelaciones de Santiago. Rol № 2390-A-91, de 12 de abril de 1991. 
San José de Costa Rica, aprobado por el Congreso Nacional y publicado en el Diario Oficial de 5 de enero de 1991, que tiene plena vigencia en nuestro país en virtud del artículo 5o de la Constitución Política, que establece que nadie será detenido por deudas y no cabe dudas que si se aceptara la interpretación del recurrente la permanencia en el recinto carcelario habría sido una prisión por deudas, expresamente prohibida en la actualidad". ${ }^{28}$

En un sentido contrario a los fallos anteriores, en el caso Garat Gálvez, la Corte Suprema el 25 de junio de 1991 se pronunció por la compatibilidad entre la ley de cheques y las disposiciones del Pacto: "En el numerando 70 el comentado artículo 70 del Pacto de San José, se asegura el derecho de que nadie será detenido por deudas, pero tal norma no resulta contrariada por el artículo 44 de la Ley de Cheques, en cuanto la caución que establece, desde que dada su naturaleza jurídica no se trata propiamente de la exigencia de una deuda civil sino que de una simple condición legal, para que los individuos privados de libertad, por los delitos descritos en esa ley, puedan obtener su excarcelación, asegurando de ese modo su comparecencia al juicio". ${ }^{29}$

El 30 de enero del año 1992, en el caso Mac Namara Verdejo, nuevamente la Corte Suprema dictó un fallo declarando la compatibilidad del artículo 44 de la Ley de Cuentas Corrientes Bancarias y Cheques y el Pacto de San José, en los mismos términos que en el caso Garat Gálvez..$^{30}$ El 17 de junio del año 1993, en el caso Pan World Trading Corporation con Alfredo Andonaegui Álvarez, la Corte decidió que las condiciones para obtener libertad provisional, establecidas en el artículo 44 de la Ley de Cheques: "No puede estimarse derogadas por otras normas constitucionales o por el Pacto de San José de Costa Rica". ${ }^{31}$

Del análisis realizado puede concluirse que la Corte de A pelaciones de Santiago desde 1991 resolvió sobre la incompatibilidad entre el artículo 44 del D.F.L. № 707 y el artículo 7 № 7 del Pacto San José de Costa Rica, toda vez que razonó que la caución de un depósito de dinero por el total de los cheques, exigida para lograr la excarcelación, constituía una prisión por deuda, que en virtud de lo dispuesto por el artículo 5o inciso segundo de la Constitución, en relación con los tratados internacionales, se encontraba prohibida. Como se observa tal "incompatibilidad" no hace más que reflejar la existencia de un conflicto entre lo dispuesto por una norma de rango legal y un tratado internacional, considerando la Corte de A pelaciones de Santiago que tal conflicto se resuelve en favor del tratado por su mayor jerarquía, aunque tal solución no se refiera siempre expresamente.

Sin embargo la Corte Suprema a partir de junio de 1991 estimó lo contrario, es decir la compatibilidad entre el señalado D.F.L y los tratados en cuestión, concluyendo

\footnotetext{
Revista Fallos del Mes, 390, pp. 130 y ss.

Revista Fallos del Mes, 391, pp. 244 y ss.

Revista de Derecho y Jurisprudencia, 89, segunda parte, sección IV, pp. 9 y ss.

31 Corte Suprema. Pan World Trading Corporation con Alfredo Andonaegui Álvarez (1993).
} 
que la caución no es una prisión por deuda, sino una condición legal para que la persona privada de libertad pueda obtener la excarcelación, asegurando así su comparecencia en juicio. Cabe señalar que el sentido de los fallos que consideran la compatibilidad entre los tratados involucrados y la ley de cheques no implican una asimilación jerárquica de tales normas, sino tan solamente se refieren a la ausencia de conflicto normativo entre aquellas.

\section{B. Casos sobre deudas previsionales}

En el caso de la Ley № 17.322, que fija normas para la cobranza judicial de imposiciones, aportes y multas de las instituciones de previsión, ${ }^{32}$ se discutió la compatibilidad del artículo 12 con el mencionado artículo 70 del Pacto San José de Costa Rica, referido a la prisión por deuda y el artículo 11 del Pacto Internacional de Derechos Civiles y Políticos. Las disposiciones internacionales fueron invocadas en esta etapa para solicitar la libertad en consecuencia de los arrestos decretados por los tribunales como medida de apremio en contra del empleador que no pagó las cotizaciones previsionales de los trabajadores.

El recurso de amparo Manuel Ugarte con AFP Santa María S.A., fue resuelto el 10 de junio de 1991 por la Corte de A pelaciones de Santiago, quien acogió el recurso de amparo interpuesto por don Manuel Ugarte para dejar sin efecto las órdenes de detención decretadas en su contra por falta de pago dentro del plazo legal de las cotizaciones establecidas en la Ley 17.322, expresándose a favor de la incompatibilidad entre el artículo 12 de la Ley 17.322 y los Pactos en cuestión, con los siguientes fundamentos: "Que atendiendo lo dispuesto en los artículos 5o y 19 № 7 de la Constitución Política del Estado y el artículo 7 № 7 del Pacto de San José de Costa Rica sobre derechos humanos, son inadmisibles los apremios por falta de pago de cotizaciones previsionales correspondientes a la Ley 17.322, pues nadie puede ser detenido por deudas". ${ }^{33}$ Este fallo fue revocado por la Corte Suprema en sentencia de 3 de diciembre de 1991, concluyendo que el artículo 12 de la Ley 17.322 no ampara legalmente la prisión por deuda y, por lo tanto, no se opone al artículo 7 № 7 de la Convención, por cuanto la conducta del empleador que no cumple con la obligación de retener y enterar las cotizaciones previsionales descontadas de la remuneración del trabajador, tipifica el delito de apropiación indebida, previsto y sancionado en el artículo

32 Señala el artículo 12 de la ley № 17.322: “El empleador que no consignara las sumas descontadas 0 que debió descontar de la remuneración de sus trabajadores y sus reajustes e intereses penales, dentro del término de quince días, contado desde la fecha del requerimiento de pago si no opuso excepciones, o desde la fecha de la notificación de la sentencia de primera instancia que niegue lugar a ellas, será apremiado con arresto, hasta por quince días. Este apremio podrá repetirse hasta obtenerse el pago de las sumas retenidas o que han debido retenerse y de sus reajustes e interese penales. El apremio será decretado, a petición de parte, por el mismo tribunal que esté conociendo de la ejecución y con el solo mérito del certificado del secretario que acredite el vencimiento del término correspondiente y el hecho de no haberse efectuado la consignación».

33 Corte de Apelaciones de Santiago. Manuel Ugarte con AFP Santa María S.A. (1991). 
470 № 1 del Código Penal y fundamenta jurídicamente la privación de la libertad que se decreta en su contra, de acuerdo a los instrumentos propios del Derecho Penal con arreglo a la Constitución y a las leyes. ${ }^{34}$

Por otro lado, en la apelación del recurso de amparo, Oliverio Fullerton Sobino con A FP Summa S.A., la Corte Suprema, en fallo del 17 de julio de 1991, dictaminó en el mismo sentido del caso anterior y se explayó: "Que el recurrente sostiene que la orden de arresto librada (...) está fuera de los casos previstos por la ley, basándose para ello en lo dispuesto en el artículo 306 del Código de Procedimiento Penal, 19 № 7 y 21 de la Constitución Política del Estado y el 7 № 7 de la Convención A mericana sobre Derechos Humanos. Que respecto de esta última disposición (...) dice el recurrente que dicho mandato imperativo es plenamente aplicable al caso de autos, pues las obligaciones previsionales perseguidas por la AFP Summa S.A. son deudas previsionales que están excluidas del apremio de arresto librado. Que la ley 17.322 señala el procedimiento que debe seguirse cuando un empleador, que ha descontado de los estipendios de los trabajadores las sumas correspondientes a cotizaciones previsionales, no ha enterado la proporción pertinente en el Instituto Previsional, estableciéndose en su artículo 12 el apremio del empleador renuente de cumplir sus obligaciones, toda vez que tratándose de cotizaciones previsionales la negativa de ese pago afecta la atención médica del trabajador y de su grupo familiar. Que, por consiguiente, la orden de arresto librada por el Juez recurrido ha sido expedida en los casos previstos por la ley, con mérito que la justifique y por autoridad competente, de tal modo que el amparo deducido debe ser rechazado". ${ }^{35}$

En el año 1992, la Corte Suprema mantuvo su posición: "Que no es procedente aplicar en la especie el Pacto de San José de Costa Rica sobre derechos humanos, por cuanto el empleador, ahora ejecutado, es un mero depositario de las sumas que descontó de la remuneración de sus trabajadores que no ingresó en el órgano previsional y, por lo tanto, no se configura la situación que prevé el referido pacto para impedir que se prive de la libertad a una persona, porque en el caso de autos no existe un incumplimiento de una obligación civil; esto es, que los dineros que se deban lo sean en virtud de una convención por la cual el deudor se obliga a efectuar ciertos pagos" ${ }^{36}$ Lo anterior fue confirmado por sentencias posteriores emanadas de la Corte Suprema. ${ }^{37-38}$

Como se observa nuevamente la Corte de A pelaciones de Santiago estuvo por resolver la incompatibilidad del artículo 12 de la Ley 17.322 y el artículo 7 № 7 del Pacto de San José de Costa Rica, otorgando preeminencia a la aplicación de este último, por cuanto reflexiona que tal privación de libertad constituye una prisión por deuda prohibida en dicho Pacto. No así la Corte Suprema que mantuvo la posición

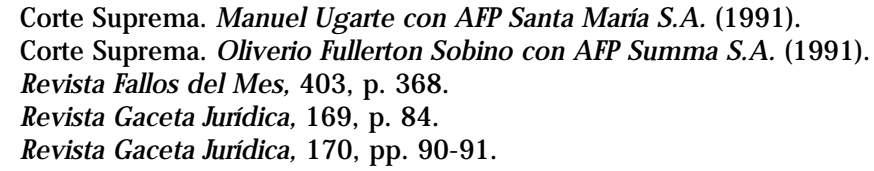


contraria, es decir, la plena justificación de la privación de libertad en la consideración de que el empleador es un mero depositario de las sumas que descontó de la remuneración de sus trabajadores que no ingresó en el órgano previsional y, por lo tanto, no se configura la situación que prevé el Pacto de San José para impedir que se prive de la libertad a una persona, porque no existe un incumplimiento de una obligación civil; esto es, que los dineros que se deban lo sean en virtud de una convención por la cual el deudor se obliga a efectuar ciertos pagos. La Corte Suprema también arguyó como fundamento que la conducta del empleador que no cumple con la obligación de retener y enterar las cotizaciones previsionales descontadas de la remuneración del trabajador, tipifica el delito de apropiación indebida, justificando jurídicamente la privación de la libertad que se decreta en su contra.

\section{Casos sobre aplicación de la ley de amnistía}

Uno de los temas que ocupó a los tribunales en esta etapa fue la compatibilidad entre el D.L. 2191 de 1978, sobre amnistía, con los tratados internacionales de derechos humanos. ${ }^{39}$

El decreto ley 2191 o ley de amnistía concedió amnistía a todas las personas, civiles o militares, que en su calidad de autores, cómplices o encubridores hubieran intervenido en hechos delictuosos acaecidos durante la vigencia de estado de sitio, en el período comprendido entre el 11 de septiembre de 1973 y el 10 de marzo de 1978, siempre que no se encontraran sometidos a proceso..$^{40}$ Este decreto ley de amnistía fue dictado en conformidad con el artículo 44 número 13 de la Constitución de 1925, que decía: "sólo en virtud de una ley se puede conceder indultos generales o amnistías".

En 1994, dos fallos sucesivos de la Corte de A pelaciones de Santiago establecieron jurisprudencia contraria a la que venía sosteniendo la Corte Suprema sobre la materia, es decir descartó la aplicación de la ley de amnistía en asuntos de secuestro y asociación ilícita, y en consecuencia que concurrieran las causales para la determinación del sobreseimiento definitivo que regulaba el artículo 413 del Código de Procedimiento Penal. Los casos son conocidos como Lumi Videla y Uribe Tambley-Van Jurick Altamirano.

39 Cabe brevemente ilustrar que la amnistía es una institución propia del derecho occidental y con carácter típicamente político, aunque lógicamente no extrajurídico, ya que su existencia está prevista conforme a Derecho. Basada por tanto en consideraciones políticas, se aplica generalmente sobre delitos políticos o relacionados con ese ámbito. La amnistía extingue la pena y sus efectos, al mismo tiempo que priva al acto penalizado su carácter de delictivo-punible y cancela los antecedentes penales y las inhabilidades a que se hubiere sometido a los amnistiados. ZúNIIGA UrBINA (1997), pp. 167-214.

40 Según el artículo 3 del D.L 2191 quedaban excluidos los que tuvieran acción penal pendiente por los delitos de parricidio, infanticidio, robo con fuerza en las cosas o con violencia o intimidación en las personas, elaboración o tráfico de estupefacientes, sustracción de menores, corrupción de menores, incendios u otros estragos, violación, estupro, manejo en estado de ebriedad, malversación de caudales o efectos públicos, fraudes y exacciones ilegales, cohecho, fraude y contrabando aduanero y delitos previstos en el Código Tributario. 
En el primero de ellos, caso Lumi Videla, la sentencia de primera instancia, dictada con fecha 10 de marzo de 1994, declaró el sobreseimiento definitivo a favor de Osvaldo Romo M ena, por el delito de secuestro y homicidio en perjuicio de Lumi Videla. La causal invocada fue la prescripción de la acción penal respecto de los crímenes cuya existencia quedó suficientemente establecida en la causa, prevista en el artículo 94 № 2 del Código Penal.

La sentencia fue apelada y la Tercera Sala de la Corte de A pelaciones de Santiago, de fecha 26 de septiembre de 1994, ${ }^{41}$ revocó la resolución del tribunal a quo, y estableció que no eran aplicables la amnistía de 1978 ni la prescripción para todos aquellos casos que ocurrieron entre el 11 de septiembre de 1973 y 10 de marzo de 1978.

La sentencia fue redactada por el abogado integrante Humberto Nogueira Alcalá y con relación a la jerarquía de los tratados internacionales el falló expresó claramente en el considerando № 9 letra a) que aquella no se encuentra prevista expresamente en la Constitución y que por lo tanto debe determinarse por vía interpretativa de la Constitución. Luego expresa la jerarquía reconocida a los tratados por la doctrina y la jurisprudencia en el considerando № 9 letras e), f), g).

Así se afirma: " 9o. a) Que para ello debemos partir del hecho de que en el ordenamiento jurídico nacional es la Constitución Política la única habilitada para determinar la existencia de otras normas, por lo que las normas de Derecho Internacional tendrían validez en la medida que la Constitución lo decidiera. Pero también la Carta Fundamental, como norma fundamental, puede remitirse a normas internacionales y que le son indisponibles en su propia validez, que resultarán aplicables junto con las producidas a través de los procedimientos internos previstos y reglados por la Constitución. b) Que la Constitución Política de la República regula el procedimiento de incorporación e integración en el ordenamiento jurídico nacional de las normas internacionales, las que una vez cumplido el procedimiento determinado por la propia Carta Fundamental, convierte a la norma internacionalmente válida en una norma internamente aplicable. (...) d) Que debemos tener presente el hecho de que como establece el artículo 50 № 1 de la Constitución, es para su aprobación por el Parlamento que el tratado debe someterse a los trámites de una ley, lo que es muy distinto a sostener que se sometan a los trámites de una ley. Nadie puede desconocer la distinta naturaleza de ambos tipos de normas y su ámbito de aplicación. En efecto, mientras la ley es un acto jurídico emanado de la voluntad unilateral de un Estado a través de los órganos colegisladores, el tratado internacional es un acto jurídico bi o multilateral que depende de la voluntad de diversos Estados y que un Estado parte no puede unilateralmente dejar sin efecto las obligaciones y derechos que emanan del tratado".

En cuanto a la jerarquía de los tratados el fallo en cuestión señala: "e) Que para la doctrina nacional los Tratados o Convenios Internacionales están ubicados necesaria-

41 Corte de A pelaciones de Santiago. Lumi Videla (1994). 
mente en una jerarquía superior a la ley, en la medida que el Estado al incorporar el tratado a su ordenamiento interno, de acuerdo al procedimiento previsto por la Carta Fundamental, quiere que sus órganos cumplan los tratados mientras no exista voluntad de denunciarlos; que, en tal sentido, se expresaron en la Comisión de Estudios de la Constitución en su sesión el 20 de junio de 1974, los comisionados A lejandro Silva Bascuñán y Jaime Guzmán Errázuriz, sin que la comisión llegara a establecer una norma expresa que determinara la jerarquía de los tratados en la Constitución. f) Que los argumentos expresados en los literales anteriores son válidos en el contexto de la Carta Fundamental de 1925, ya que las disposiciones constitucionales que regulan la incorporación y aplicación de los tratados internacionales bajo dicha carta, son prácticamente idénticas a las que establece la Carta de 1980. g) Que la jurisprudencia de los tribunales superiores de justicia se ha ido asentando en el sentido de dar primacía a los tratados sobre la ley interna, tanto bajo la Carta de 1925, como bajo el imperio de la Constitución actual. Algunos ejemplos de ello constituyen las sentencias Lauritzen con Fisco de 1955; el caso de extradición activa de 1959 (Revista de Derecho y Jurisprudencia Tomo LVI, 2a parte, Sección Cuarta, pág. 66); el caso Embajada de la República de China (Fallos del Mes, septiembre de 1969, páginas 223 y 224); el caso Presidente del Consejo de Defensa del Estado y Embajada de Cuba de 1975 (Revista Fallos del Mes, junio de 1975, página 90); el fallo sobre ejercicio de las profesiones liberales (aplicación de la Convención México de 1902); los casos de aplicación de la Convención de Derechos del Niño en materia de libertad provisional (sentencia Rol No 19.558 94 Corte de A pelaciones de Santiago), entre otros. h) Que la Constitución Política de la República no fundamenta la validez de la norma internacional sino sólo su aplicabilidad. Una vez incorporado al Derecho Interno, es la propia convención internacional la que decide cómo deben ser aplicadas sus normas, una vez que la Constitución las ha hecho aplicables, inaplicando las leyes que se ocupan de la misma materia que el tratado incorporado al ordenamiento nacional, lo que se desprende del hecho que es el propio Congreso que aprueba las leyes el que va a aprobar el tratado internacional antes de su ratificación. (...) A sí, la Constitución sólo es competente para dar al tratado el carácter de aplicable, siendo el Derecho Internacional el que determine la forma en que deben ser aplicadas las normas creadas por él (...) m) Que, por lo tanto, ante una contradicción entre ley y tratado, el problema no se plantea en el ámbito de la validez de tales normas sino que se plantea en el terreno de la aplicabilidad (...)".

Por su parte, en el caso Uribe Tambley-Van Jurick Altamirano, la Octava Sala de la Corte de A pelaciones de Santiago confirmó la sentencia de la primera instancia y por lo tanto se confirmó el auto de procesamiento respectivo en cuyo favor se había interpuesto el recurso, que al igual que en el caso anterior era Osvaldo Romo Mena, todo esto con fecha 30 de septiembre de $1994 .{ }^{42}$ El fallo, redactado por el abogado integrante Humberto Nogueira Alcalá, resuelve que son aplicables al caso los Convenios de Ginebra de 1949, que disponen que los delitos por ellos contemplados son imprescriptibles e inamnistiables. Tales convenios internacionales se encuentran plenamente

42 Corte de A pelaciones de Santiago. Osvaldo Romo Mena (1994). 
vigentes en Chile y son aplicables en caso de guerra, precisando que en Chile existía un estado de guerra interna al momento de ser secuestrados y luego torturados Bárbara Uribe Tambley y Edwin Van Jurik en 1974, situación que a juicio de los sentenciadores ocurría en el país de conformidad a las diferentes declaraciones realizadas por el gobierno de la época, especialmente la declaración de estado de sitio.

En relación con la jerarquía de los tratados, el considerando № 6 del fallo expresa, en iguales términos que el considerando № 9 del caso Lumi Videla, que es necesario determinar el sentido y alcance que tienen los tratados internacionales en el ordenamiento jurídico chileno, ya que en la Constitución no hay norma expresa que le dé una categoría determinada entre las fuentes del derecho, por lo que ello debe determinarse por vía interpretativa.

En el considerando № 6. e), el fallo señala la posición jerárquica que le atribuye la doctrina, especialmente la que le reconocieron algunos miembros de la Comisión Ortúzar en la elaboración del Anteproyecto de Constitución: "Que para la doctrina nacional los Tratados o Convenios Internacionales están ubicados necesariamente en una jerarquía superior a la ley, en la medida que el Estado al incorporar el tratado a su ordenamiento interno, de acuerdo al procedimiento previsto por la Carta Fundamental, quiere que sus órganos cumplan los tratados mientras no exista voluntad de denunciarlos; que, en tal sentido, se expresaron en la Comisión de Estudios de la Constitución en su sesión el 20 de junio de 1974, los comisionados A lejandro Silva Bascuñán y Jaime Guzmán Errázuriz, sin que la comisión llegara a establecer una norma expresa que determinara la jerarquía de los tratados en la Constitución".

En el considerando № 6.g), el fallo menciona la posición que la jurisprudencia le reconoce a los tratados, refiriendo incluso algunos casos: "Que la jurisprudencia de los tribunales superiores de justicia se ha ido asentando en el sentido de dar primacía a los tratados sobre la ley interna, tanto bajo la Carta de 1925, como bajo el imperio de la Constitución actual. Algunos ejemplos de ello constituyen las sentencias Lauritzen con Fisco de 1955; el caso de extradición activa de 1959 (Revista de Derecho y Jurisprudencia, Tomo LVI, 2a parte, Sección Cuarta, pág. 66); el caso Embajada de la República de China (Fallos del M es, septiembre de 1969, páginas 223 y 224); el caso Presidente del Consejo de Defensa del Estado y Embajada de Cuba de 1975 (Revista Fallos del Mes, junio de 1975, página 90); el fallo sobre ejercicio de las profesiones liberales (aplicación de la Convención México de 1902); los casos de aplicación de la Convención de Derechos del Niño en materia de libertad provisional (sentencia Rol № 19.55894 Corte de A pelaciones de Santiago), entre otros".

En el considerando 6.n) del fallo se establece la forma de resolver un conflicto normativo cuando una de las normas en cuestión es un tratado: "Que, por lo tanto, ante una contradicción entre ley y tratado, el problema no se plantea en el ámbito de la validez de tales normas sino que se plantea en el terreno de la aplicabilidad, ámbito dentro del cual debe decidir el juez ordinario, aplicando preferentemente el tratado". 
En el considerando № 7.b) se expresa que la finalidad de la reforma constitucional del año 1989 al inciso segundo del artículo 5o fue elevar la jerarquía de los tratados internacionales de derechos humanos: "Que, a su vez, el constituyente de 1989, agregó, con el objeto de reforzar la garantía de los derechos y establecer objetivamente el plexo fundamental de derechos asegurados, como asimismo, para elevar de jerarquía a los tratados internacionales de derechos humanos, la frase final del inciso $20 \mathrm{del}$ artículo 5 de la Constitución: Es deber de los órganos del Estado respetar y promover tales derechos, garantizados por la Constitución, así como por los tratados internacionales ratificados por Chile y que se encuentran vigentes".

En el considerando № 8 se expresa la mayor jerarquía de los tratados en relación con la ley: "Que, siendo los convenios de Ginebra normas obligatorias para el Estado de Chile desde abril de 1951, y teniendo sus disposiciones una protección de los derechos humanos de los contendientes en caso de guerra externa o conflicto entre fuerzas organizadas de carácter armado internas al Estado, situación esta última vigente en el país en 1974, como consta del fundamento 5o, de acuerdo con lo cual y teniendo presente los argumentos de los fundamentos 6 y 70, en relación a la aplicación de las normas de los Tratados Internacionales, en especial, de aquellos que garantizan derechos humanos, estos prevalecen sobre las normas legales anteriores 0 posteriores de carácter interno, mientras el Estado de Chile no haya denunciado los convenios internacionales por medio del procedimiento establecido en ellos mismos".

En ambos fallos, considerandos № 18 del caso Lumi Videla y № 15 del caso Uribe Tambley-Van Jurick, se expresó: “Que, esta Corte se encuentra vinculada por la Constitución Política de la República y por los Pactos Internacionales de Derechos Humanos ratificados por Chile y que se encuentran vigentes, teniendo el deber constitucional de respetarlos y promoverlos, no pudiendo sustraerse de tal obligación constitucional establecida en las Bases de la Institucionalidad, artículo 50 inciso 20 de la Constitución, sin incurrir en notable abandono de deberes, como asimismo, exponer la seguridad y el honor del Estado de Chile en el campo internacional y debilitar el Estado de Derecho y los principios del constitucionalismo democrático que constituyen el soporte ético y jurídico de la Carta Fundamental y de la Nación Chilena".

Respecto de ambas resoluciones se entablaron recursos de queja, los que fueron finalmente fallados por la Corte Suprema en el año 1995, caso Uribe Tambley-Van Jurick, y en 1996, caso Lumi Videla. ${ }^{43}$ En ambos supuestos se revocaron las sentencias anteriores y la Corte declaró inaplicables a la situación referida en las sentencias de apelaciones (guerra o conflicto armado interno) las normas convencionales del derecho internacional humanitario, incluyendo el Protocolo II de 1979, fundamentalmente por no darse los supuestos bélicos allí contemplados. ${ }^{44}$

43 Corte Suprema. Romo Mena Osvaldo (Lumi Videla Moya), (1996).

44 En el primero de ellos, la Corte, luego de hacer un análisis de las Convenciones de Ginebra, señala en el considerando № 13: “Que en relación a los demás Tratados internacionales a que se ha hecho mención, es necesario señalar que sus disposiciones sólo son aplicables desde la fecha de su publicación en el 
Las conclusiones que se pueden extraer de los fallos dictados por la Corte de Apelaciones de Santiago en los casos Lumi Videla y Uribe Tambley-Van Jurick, son, en primer lugar, que la incompatibilidad entre la ley de amnistía con los tratados sobre derechos humanos, se resuelve aplicando preferentemente los tratados por sobre la ley interna, con base en el rango supralegal de los mismos. Por otro lado, la amnistía como causal de extinción de la responsabilidad penal y que afecta al propio hecho punible, se encuentra prohibida expresa o implícitamente por convenios internacionales de los cuales Chile es parte, entre ellos las Convenciones de Ginebra sobre derecho internacional humanitario de 1949, los Protocolos Adicionales de 1977, el Pacto Internacional de Derechos Civiles y Políticos de 1966, la Convención contra la tortura y otros tratos o penas crueles, inhumanas o degradantes de las Naciones Unidas de 1984, la Convención Americana sobre Derechos Humanos de 1969, la Convención Interamericana para prevenir o sancionar la tortura de 1987 y la Convención sobre la Prevención y Castigo del Crimen de Genocidio de 1948. ${ }^{45}$

\section{TERCERA ETAPA DE EVOLUCIÓN JURISPRUDENCIAL: 1994-2005}

La tercera etapa de Evolución Jurisprudencial se extiende desde el año 1994 hasta el año 2005, en el que se dictó por la Corte Interamericana de Derechos Humanos el fallo Almonacid Arellano vs. Chile. En esta etapa pueden apreciarse dos grupos de materias en las cuales recaen los pronunciamientos sobre la jerarquía de los tratados: deudas previsionales y aplicación de la ley de amnistía.

\section{A. Casos sobre deudas previsionales}

Por muchos años la Corte Suprema mantuvo su postura en cuanto a no considerar lo previsto por los tratados internacionales en lo relativo a la prisión por deuda alegada por quienes eran privados de libertad por el no pago de cotizaciones previsionales; sin embargo en el año 2004 se observa un cambio y en sentencia recaída en recurso

Diario Oficial. Ello, en virtud del principio de irretroactividad de la ley penal consagrado en la Carta Fundamental (...), y que complementa el artículo 18 del Código Penal. Por lo tanto, no puede pretenderse que ellos tengan aplicación a situaciones o hechos acaecidos con anterioridad a su incorporación al Derecho Interno. Es más, la Convención de Viena sobre Derecho de los Tratados (Diario Oficial del 22 de julio de 1981) en relación con la aplicación de los tratados, establece en su artículo 28: "Las disposiciones de un Tratado no obligarán a una parte respecto de ningún acto o hecho que haya tenido lugar con anterioridad a la fecha de entrada en vigor del tratado para esa parte ni de ninguna situación que en esa fecha haya dejado de existir". Por otro lado, la Corte Suprema al acoger los recursos de queja afirma que del Derecho Internacional Humanitario no se deriva la prohibición de la amnistía. A mayor abundamiento hace referencia a la disposición contenida en su artículo 6 párrafo 5 del Protocolo II, según el cual: "A la cesación de las hostilidades, las autoridades, en el poder procurarán conceder la amnistía más amplia posible a las personas que hayan tomado parte en el conflicto armado o que se encuentren privadas de libertad, internadas o detenidas por motivos relacionados con el conflicto armado". El fallo de la Corte Suprema sobre el caso Lumi Videla es muy similar, por lo que no se repiten sus argumentos.

45 Nogueira Alcalá (1995), p. 84. 
de amparo a favor de Handel Sepúlveda Tapia, ${ }^{46}$ sostuvo que el arresto por el no pago de las deudas previsionales constituye una prisión por deuda. Así en el considerando 5 o indicó: "Que las órdenes de arresto han sido dispuestas en contra de las normas anteriormente invocadas, con lo cual se atenta en contra de la garantía constitucional invocada por el recurrente, por constituir una amenaza ilegítima a la libertad personal del recurrente, ya que el pago compulsivo de una cotización previsional constituye prisión por deuda, proscrita de nuestro sistema jurídico".

En el considerando № 2 de esta sentencia se sostiene expresamente que los derechos consagrados en los tratados internacionales se incorporan a la Constitución material: "Que, de acuerdo con el artículo 5o, inciso 2 de la Carta Fundamental, los derechos asegurados en los tratados se incorporan al ordenamiento jurídico interno, formando parte de la Constitución material y adquiriendo plena vigencia, validez y eficiencia jurídica, no pudiendo ningún órgano del Estado desconocerlos, y debiendo todos ellos respetarlos y promoverlos, como asimismo, protegerlos a través del conjunto de garantías constitucionales destinadas a asegurar el pleno respeto de los derechos".

Con relación a la jerarquía de los tratados, el considerando № 3 dispone: "Que de lo expuesto, cabe concluir que el Pacto de San José de Costa Rica tiene una jerarquía superior a la ley 17.322, y que, por lo demás, al haber sido esta ley publicada en 1970, fue derogada tácitamente por el pacto, cuya publicación en el Diario Oficial es posterior".

A simismo en el año 2004, la Corte de A pelaciones de Rancagua en sentencia recaída en recurso de amparo a favor de Cristián M iranda Pérez, estimó que la privación de libertad por el no pago de deudas previsionales constituye una prisión por deuda. ${ }^{47}$ Con respecto a la jerarquía del Pacto de San José de Costa Rica invocado por el recurrente, el fallo señaló en el considerando № 8 que: "A tendido lo referido en las consideraciones precedentes, debe concluirse en que el Pacto de San José de Costa Rica tiene un rango superior a la ley 17.322, la que fue derogada por el pacto, ya que su publicación en el Diario Oficial fue el 5 de enero de 1991, muy posterior a la publicación de la citada ley, 19 de agosto de 1970".

El mismo año 2004, la Corte Suprema resolvió revocar la sentencia apelada de 30 de marzo de 2004 y acoger el recurso de amparo, dejando sin efecto los arrestos decretados en contra de Mauricio Pinto Meneses. ${ }^{48}$ En este caso, la sentencia de la

46 Corte Suprema. Handel Sepúlveda Tapia con Carlos Iván Gutiérrez Zavala Juez Letrado Titular del Primer Juzgado Civil de Temuco; Segundo Juzgado Civil de Temuco; Tercer Juzgado Civil de Temuco (2004). Acordada contra el voto de los Ministros Chaigneau y Segura, quienes estuvieron por rechazar el recurso de amparo, estimando para ello que el apremio de que se trata ha sido dictado por autoridad competente, en un caso previsto por la ley y existiendo mérito suficiente que lo justifique.

47 Corte de A pelaciones de Rancagua. A.F.P. Magíster con Cristián Alberto Miranda Pérez (2004).

48 Corte Suprema. Mauricio Pinto Meneses con Juez del Séptimo Juzgado del Trabajo de Santiago (2004). A cordado con el voto en contra de los M inistros Chaigneau y Segura, quienes estuvieron por confirmar la resolución de la Corte de A pelaciones de Santiago y estuvieron por disponer que el Juez del Trabajo ponga en conocimiento del Juzgado del Crimen respectivo los antecedentes de las causas laborales para los efectos previstos en el artículo 13 de la ley № 17.322 . 
Corte de Apelaciones de Santiago fue acordada con el voto en contra del abogado integ rante Hugo Llanos M ansilla, quien estuvo por acoger el recurso de amparo interpuesto. Los fundamentos esgrimidos por el abogado integrante dicen relación con lo previsto en el Pacto de San José de Costa Rica, al que le reconoce rango constitucional. En el considerando $1^{\circ}$ del voto disidente expone: "El artículo 5o le otorga así, rango constitucional a los tratados que garantizan el respeto a los derechos humanos, concediéndoles una jerarquía mayor que a los demás tratados internacionales". Para reforzar su voto, el abogado integrante Hugo Llanos $M$ ansilla, detalla extensamente la posición de una parte de la doctrina nacional, destacando a Francisco Cumplido y Humberto Nogueira; además cita jurisprudencia de la Corte Suprema. Finalmente concluye en los considerandos Nos 3o y 40: "3‥ Que, de lo expuesto, cabe concluir que el Pacto de San José de Costa Rica tiene una jerarquía superior a la ley № 17.322 y que, por lo demás, al haber sido esta ley publicada en 1970, fue derogada por el Pacto, cuya publicación, en el Diario Oficial, fue posterior: el 5 de enero de 1991. 4\%. Que, el Pacto de San José de Costa Rica, en su artículo 7 № 7, al señalar que «nadie puede ser detenido por deudas», admitió una sola excepción: «os mandatos de autoridad jurisdiccional competente dictados por incumplimiento de deberes alimentarios", por lo que no puede ampliarse su interpretación para incluir, además, las deudas previsionales".

La sentencia de la Corte Suprema en este caso hace suyos los fundamentos del voto disidente del abogado integrante Hugo Llanos Mansilla, en el entendido que la orden de arresto fue dispuesta en contra de las normas de los tratados internacionales de derechos humanos invocados por el recurrente, constituyendo una amenaza ilegítima a la libertad personal: "(... ) ya que el pago compulsivo de una cotización previsional constituye una prisión por deuda proscrita de nuestro sistema jurídico".

En el año 2004, la Corte Suprema cambió nuevamente su postura y en sentencia recaída en la apelación de un recurso de amparo interpuesto a favor de Leonel Huerta Corrales confirmó la decisión apelada y rechazó el recurso, entendiendo que no puede estimarse que la retención de las cotizaciones a los trabajadores y su no pago a la entidad previsional correspondiente constituya un supuesto propio de una prisión por deuda de aquellas que proscribe la Convención Americana de Derechos Humanos, toda vez que en la especie se trata de retenciones efectuadas a los sueldos de los trabajadores con esa precisa finalidad por el amparado en su condición de representante legal de la empresa empleadora. ${ }^{49}$

En relación con lo analizado, puede concluirse que la jurisprudencia de la Corte Suprema en esta etapa y en materia de arresto por no pago de cotizaciones previsio-

49 Corte Suprema. Leonel Huerta Corrales con Eliana Silva Romero Juez del Noveno Juzgado del Trabajo de Santiago (2004). A cordado con el voto en contra del Ministro Sr. Cury, quien estuvo por revocar la referida sentencia y acoger el recurso de amparo, por estimar que el apremio decretado constituye una amenaza ilegítima a la libertad personal del recurrente ya que el pago compulsivo de una cotización previsional deriva de una actuación que importa una prisión por deuda que en nuestro sistema jurídico está proscrita y, en atención a lo dispuesto en el artículo 7 № 7 del Pacto de San José de Costa Rica en relación a lo establecido en el artículo 50 de la Constitución Política de la República. 
nales fue vacilante. Esto, toda vez que en algunos fallos consideró tal arresto como prohibido por los tratados internacionales, por tratarse de una prisión por deuda, y en otros caso negó la aplicación de los tratados, argumentando tratarse el empleador de un mero depositario de las sumas que descontó de la remuneración de sus trabajadores que no ingresó en el órgano previsional y, por lo tanto, no se configura la situación que prevé el Pacto para impedir que se prive de la libertad a una persona, porque no existe un incumplimiento de una obligación civil.

Cabe señalar que cuando la Corte Suprema identificó la incompatibilidad entre el Pacto de San José de Costa Rica y el artículo 12 de la Ley 17.322, le atribuyó mayor jerarquía al tratado que a la ley, haciendo aplicable el Pacto.

\section{B. Casos sobre aplicación de la ley de amnistía}

En el caso Carmelo Soria, el 4 de junio de 1996, la sentencia del M inistro Instructor Eleodoro Ortiz resolvió aplicar el D.L. 2191 a la litis sobre la base de considerar la imposibilidad de que los tratados de derechos humanos rijan a situaciones acaecidas con anterioridad a su vigencia. En este caso el juez fijó la vigencia del tratado en comento a partir de la incorporación de la parte final al inciso segundo del artículo 50 en 1989. Sus argumentos en ese sentido se encuentran en el considerando № 13: "Que, habría que añadir, (...) que la modificación introducida al artículo 5o de la Constitución (...) sólo puede tener eficacia hacia el futuro, y no puede ser aplicada con efecto retroactivo, desde que no hay ninguna norma que así lo señale en forma expresa". Luego en el considerando № 14 establece: "Que también habría que agregar que al aplicar a este caso, el decreto ley 2191 de 1978, no se están vulnerando otros tratados internacionales sobre derechos humanos, puesto que ellos son de vigencia posterior a la del decreto ley y porque este no ha impedido que se realice la más exhaustiva investigación posible sobre los hechos que culminaron con la muerte del Señor Soria". 50

Como se observa en este razonamiento, el juez en cuestión reconoce la misma jerarquía de la ley al tratado, tanto así que para resolver el conflicto normativo utilizó el criterio de temporalidad o cronológico. Sin embargo, el razonamiento planteado en el fallo del Ministro Ortiz es incorrecto en cuanto a que los tratados adquieren vigencia y son obligatorios en la oportunidad que señalan aquellos o conforme a lo dispuesto por el Derecho internacional convencional y no a partir de que la Constitución los reconoce como fuente del Derecho interno.

En otro fallo, de fecha 11 de marzo de 1998, caso Andrés Pereira Salsberg y otros, la Corte Suprema dictaminó en relación con la jerarquía de los tratados que: "8o. Que a mayor abundamiento, por lo regular, con anterioridad a la modificación del artículo 5o de la Constitución Política de la República, que recién con fecha 17 de agosto de

50 Revista de Derecho y Jurisprudencia, 93, segunda parte, sección IV, p. 119. 
1989 subordinó a los tratados internacionales ratificados por Chile y relativos a los derechos humanos, la ley chilena, se impuso el criterio de que, al menos las leyes nacionales de orden público, tienen preeminencia sobre las disposiciones de tratados o convenciones internacionales (v. gr. Revista de Derecho y Jurisprudencia, Tomo XL, 2 a parte, sección 4ạ, pág. 186). No está de más hacer notar que las normas del recordado D.L. 2191, precisamente de orden público como se ha dicho, han sido aplicadas hasta ahora en multitud de casos (...)"..11

Como se advierte en este fallo, la Corte Suprema hace un distingo en cuanto a la jerarquía de los tratados. Por un lado reconoce que los tratados de derechos humanos tienen "preeminencia" sobre las leyes internas, es decir mayor rango jerárquico; sin embargo, por otro, considera como excepción a esta regla a las leyes de orden público, las que se imponen sobre los tratados. Tal es el caso de la ley de amnistía que la sentencia considera norma de orden público. ${ }^{52}$

Como se observa, a partir del caso Carmelo Soria de 1996, la Corte Suprema reconoce igual jerarquía a los tratados que a las leyes, resolviendo el conflicto entre los tratados y la ley de amnistía por la vía del criterio de la temporalidad. Sin embargo, a partir de 1998 reconoce que los tratados de derechos humanos son jerárquicamente superiores a las leyes comunes, pero jerárquicamente inferiores a las leyes de orden público y por tal razón se abandona el criterio de la temporalidad para dar paso a la aplicación del criterio jerárquico.

Empero, el 9 de septiembre de 1998, la Corte Suprema en sentencia de casación recaída en el caso Poblete Córdova, rompió con su sostenida tradición de aplicar la ley de amnistía y comenzó a considerar aplicable al caso lo previsto en los tratados internacionales..$^{53}$ Sostuvo la Corte en el considerando № 10: "Que, en consecuencia, el Estado de Chile se impuso en los citados Convenios (de Ginebra) la obligación de garantizar la seguridad de las personas que pudieron tener participación en conflictos armados dentro de su territorio, especialmente si fueren detenidas, quedando vedado el disponer medidas que tendieran a amparar los agravios cometidos contra personas

51 Corte Suprema, Pereira Salberg, Andrés y otros (2004).

52 Similares argumentos a los ya citados continuaron sosteniéndose en sentencias posteriores, de fechas 19 de agosto y 8 de septiembre de 1998. Con respecto a esta última, la Corte Suprema en el considerando № 10 reiteró que las leyes de orden público, como la ley de amnistía, se aplican con preeminencia sobre los tratados, aclarando al mismo tiempo que luego de la reforma de 1989 al artículo 50 inciso segundo las leyes chilenas quedan subordinadas a los tratados: "Que no está de más consignar, que, por lo regular, con anterioridad a la modificación del artículo 50 de la Constitución, que recién con fecha 17 de agosto de 1989 subordinó a los tratados internacionales ratificados por Chile en materia de derechos humanos, la ley chilena, se impuso el criterio de que, al menos las leyes nacionales de orden público, tienen preeminencia sobre las disposiciones de tratados o convenciones internacionales (v. $\mathrm{gr}$. Revista de Derecho y Jurisprudencia, tomo XL, $2^{a}$ parte, sección 4a normas del decreto ley № 2.191, precisamente de orden público, han sido aplicadas hasta ahora, en multitud de casos, en provecho y beneficio de personas de distinta y antagónica ideología política". Corte Suprema, Lauriani, Fernando y Romo, Osvaldo (1998).

53 Corte Suprema, Poblete Córdova (1998). 
determinadas o lograr la impunidad de sus autores, teniendo especialmente presente que los acuerdos internacionales deben cumplirse de buena fe. $Y$, en cuanto el Pacto (Pacto Internacional de los Derechos Civiles y Políticos) persigue garantizar los derechos esenciales que emanan de la naturaleza humana, tiene aplicación preeminente, puesto que esta Corte Suprema, en reiteradas sentencias ha reconocido que de la historia fidedigna del establecimiento de la norma constitucional contenida en el artículo 5o de la Carta Fundamental queda claramente establecido que la soberanía interna del Estado de Chile reconoce su límite en los derechos que emanan de la naturaleza humana; valores que son superiores a toda norma que puedan disponer las autoridades del Estado, incluido el propio Poder Constituyente, lo que impide que sean desconocidos (...) En la parte final del considerando № 10 la Corte Suprema insiste en reconocer mayor jerarquía a los tratados en relación con la legislación interna, cuando señala que la legislación interna debe adecuarse a los tratados evitando transgredir sus principios: "En tales circunstancias omitir aplicar dichas disposiciones importa un error de derecho que debe ser corregido por la vía de este recurso, en especial si se tiene presente que de acuerdo a los principios del Derecho Internacional los Tratados Internacionales deben interpretarse y cumplirse de buena fe por los Estados; de lo que se colige que el Derecho Interno debe adecuarse a ellos y el legislador conciliar las nuevas normas que dicte a dichos instrumentos internacionales, evitando transgredir sus principios, sin la previa denuncia de los Convenios respectivos".

Finalmente el considerando № 11 establece: “Que, en otra perspectiva, ha de considerarse que se dio comienzo a la perpetración de los hechos el 19 de julio de 1974, ignorándose hasta esta la fecha el destino y paradero de Pedro Poblete Córdova, por lo que es posible que el o los ilícitos que hubieren de establecerse excedieran el ámbito temporal sustantivo de aplicación del decreto ley № 2.191".

Como se advierte, a finales de 1998 y a partir del caso Poblete Córdova, la Corte Suprema estimó que los Convenios de Ginebra eran plenamente aplicables a los casos, porque a la época de comisión de los supuestos ilícitos se vivió un "estado de guerra". Entendió, como consecuencia de lo anterior, que dichos convenios impedían la aplicación de la ley de amnistía en la instancia procesal en que se encontraba la causa, por dos razones: se trataba de delitos cuya extrema gravedad hacían necesaria la prosecución de la investigación, a fin de determinar el tipo penal. Por otro lado, por corresponder los hechos a un tipo penal no amnistiable según los Convenios de Ginebra, es decir un delito de lesa humanidad.

En el, año 2003, la Corte Suprema resolvió sobre dos recursos de casación en el fondo, recayendo sendas sentencias el 31 de enero de 2003, con similares razonamientos en torno a la no aplicación de la ley de amnistía.

En la primera decisión, caso A randa Romero, el recurrente planteó la casación en el fondo con fundamento en la causal № 6 del artículo 546 del Código de Procedimiento Penal, sosteniendo que se cometió un error de derecho al decretar el sobreseimiento definitivo por la causal del artículo 408 № 5 del Código de Procedimiento Penal, en 
relación con los artículos 93 № 3 del Código Penal y 1o del decreto ley № 2191, 141 y 148 del Código Penal y 413 del Código de Procedimiento Penal. Citó, además, como normas infringidas, disposiciones de la Convención Americana de Derechos Humanos, del Pacto Internacional de Derechos Civiles y Políticos y los Convenios de Ginebra. ${ }^{54}$

En la segunda decisión, originada en el secuestro de Nelson Almendras, José López, Juan Briones, José Hernández y Victoriano Lagos, la Corte Suprema estimó inaplicable la ley de amnistía. ${ }^{55}$ Los fundamentos esgrimidos por el recurrente y la Corte Suprema fueron los mismos que los planteados en el caso anterior.

Cabe decir, que en ambos casos el Informe del Fiscal Judicial señaló que debía acogerse el recurso de casación en el fondo, invalidarse la sentencia de sobreseimiento y disponer que continúe la investigación. A esta conclusión llega, en parte, considerando lo previsto por los tratados internacionales, respecto de los cuales analiza su jerarquía, atribuyéndoles un rango superior a la legislación. El Fiscal asume que al caso son aplicables los Convenios de Ginebra, la Convención Americana sobre Derechos Humanos, la Carta de la Organización de los Estados A mericanos, la Declaración Universal de los Derechos y Deberes del Hombre y la Declaración Universal de los Derechos Humanos. A simismo, consideró que lo dispuesto en el inciso 20 del artículo 50 de la Constitución es claro al imponer a todos los órganos del Estado un deber, que prima sobre cualquiera otro establecido en la legislación, y que consiste en garantizar y hacer respetar los derechos que emanen de cualquier tratado internacional que Chile haya ratificado y que se encuentre vigente, y el respeto de los derechos esenciales

54 Corte Suprema, Alejandro González Poblete; Consejo Superior Corporación Nacional Reparación con, (2003). En los considerandos $N^{\circ s} 3$ y 4 , la Corte estimó que no se ha dado una correcta aplicación a la norma del artículo 408 № 5 del Código de Procedimiento Penal, pues esta última establece que el sobreseimiento definitivo por alguna de las causales del artículo 93 del Código Penal se decretará en beneficio de un procesado, concepto que en un sentido amplio debe entenderse tanto respecto del procesado propiamente tal, como también respecto del inculpado o imputado a quien pueda aplicarse alguno de los numerales que señala la disposición adjetiva que se analiza. Que también se ha hecho una incorrecta aplicación del artículo 93 № 3 del Código Penal, pues la amnistía se aplica a personas determinadas y no a hechos punibles. En los considerandos Nos 7 y 8 , la Corte concluyó que no se ha dado una correcta aplicación a la norma del artículo 413 del Código de Procedimiento Penal, pues esta última disposición establece que el sobreseimiento definitivo se decretará siempre que esté agotada la investigación con que se haya tratado de comprobar el hecho punible y de determinar la persona del delincuente, infracción que se ha cometido porque el Tribunal Militar no sólo no investigó, sino que dejó sin efecto de hecho diligencias decretadas por el tribunal del fuero ordinario y procedió de inmediato a sobreseer definitivamente la causa. Que también se infringió el artículo 148 del Código Penal, pues esta figura sanciona un hecho punible de carácter permanente, y mientras no se sepa con exactitud qué fue lo que sucedió en definitiva con el detenido, no sería posible aplicar la amnistía del decreto ley № 2191, aun cuando se conociera quién o quiénes fueron los autores del hecho, pues dicha legislación se aplica dentro de un período determinado, y no se sabe con exactitud si al término de dicho período ocurrido el 10 de marzo de 1978, Aranda Romero continuaba detenido o no y cuál era su estado Acordada contra el voto del Auditor General del Ejército, señor Juan Romero Riquelme, quien fue del parecer rechazar el recurso de casación en el fondo.

55 Corte Suprema, Corporación Nacional Reparación Reconciliación con (2003). 
que emanan de la naturaleza humana. En sus propios términos señala: "En esta forma el artículo 5o inciso 2o de la Constitución dio especial realce al Convenio de Ginebra relativo a la protección de personas civiles en tiempos de guerra, de 12 de agosto de 1949, suscrito y ratificado por Chile, y a la Convención A mericana de Derechos Humanos o «Pacto de San José de Costa Rica». (... ) Las convenciones citadas son anteriores en el tiempo al decreto ley sobre amnistía, y las normas constitucionales, si bien son posteriores, deben recibir aplicación porque aquí no existe un problema sobre retroactividad de la ley, ya que es la propia norma constitucional la que ha fijado la obligación a la autoridad de privilegiar lo pactado internacionalmente con respecto a toda disposición interna. El alcance de dicha norma no quebranta los derechos y garantías que ella establece por cuanto es el basamento jurídico de la Nación que lo determina y su decisión sólo puede ser modificada en la forma que su propio articulado dispone. Su valor jurídico no puede alterarse salvo que se resuelva hacerlo de la manera que ella lo fija. Es así, entonces, que no se quebranta ningún derecho adquirido si se da preeminencia a las convenciones internacionales y a las normas constitucionales citadas. En el caso del decreto ley No 2.191, la sanción de los delitos está en el Código Penal de 1874 y recibe debida aplicación el precepto legal del artículo 18 del mismo cuerpo legal".

Finalizando esta etapa, en diciembre del año 2004, la Corte de Apelaciones de Temuco conoció la apelación del caso Ricardo Rioseco Reyes con Joaquín León Rivera, originado por el homicidio calificado de Ricardo Rioseco M ontoya y Luis Cotal Álvarez. ${ }^{56} \mathrm{La}$ Corte de A pelaciones de Temuco, siguiendo los razonamientos de la Corte de A pelaciones de Santiago en el caso Uribe Tambley-Van Jurick, estimó que a la fecha del acaecimiento de los hechos delictuosos, el país estaba en estado de guerra, en mérito de lo previsto en el Decreto Ley № 5 de 12 de septiembre de 1973, estado que se mantuvo hasta el 11 de marzo de 1975, a raíz de los decretos leyes 640 y 641 de septiembre de 1974. Asimismo la Corte de A pelaciones consideró que en esta época regía la Constitución de 1925 y la legislación internacional vigente en Chile, tales como los Convenios de Ginebra del año 1949 sobre Derecho Humanitario Internacional, los que establecen que los delitos de homicidio son imprescriptibles e inamnistiables, porque constituyen ilícitos que afectan los derechos humanos configurando delitos de lesa humanidad, que no permiten ni son afectados por prescripción ni amnistía. En cuanto a la jerarquía de los tratados internacionales esta sentencia sigue los razonamientos del caso Uribe Tambley-Van Jurick y en los considerandos $N^{\circ s} 4$ y 5 reprodujo tal fallo reconociendo jerarquía supralegal a los tratados de derechos humanos. ${ }^{57}$

56 Corte de Apelaciones de Temuco. Ricardo Rioseco Reyes con Joaquín León Rivera (2004).

57 Destacan los considerandos 4 y 5: “(... d) En su tramitación la aprobación de tratado se somete a los trámites de una ley, lo que significa: 1) que el tratado se incorpora al derecho interno, forma parte de él; 2) que esta incorporación implica la plena validez del tratado, pues una vez aprobado regirá en el orden interno y su sentido y alcance debe analizarse conforme a su propio mérito, pues ese es el compromiso que el Estado ha asumido de acuerdo a las normas constitucionales que se han invocado; 3) que la norma internacional prima sobre la norma interna cuando existe contradicción entre una y otra, la condiciona o modifica si en el caso concreto debe aplicarse la norma internacional, puesto que al aprobar el tratado y al no haberse hecho reserva por el Congreso, la norma internacional como norma nueva modifica en lo pertinente a la norma interna, pues ha pasado a ser norma interna o de aplicación interna o en caso de ser 
Como se advierte en esta etapa, las sentencias de los tribunales superiores de justicia, comienzan a inaplicar la ley de amnistía considerando que pugna con lo previsto en los tratados internacionales, especialmente aquellos que forman parte del Derecho Internacional Humanitario. Claramente la decisión de los tribunales en este sentido señala el reconocimiento de una mayor jerarquía de los tratados sobre la legislación interna, posición que terminará por arraigarse en la etapa siguiente y concluida de manera expresa en las correspondientes sentencias.

\section{CUARTA ETAPA DE EVOLUCIÓN JURISPRUDENCIAL: DESDE EL AÑO 2005 A LA ACTUALIDAD}

La cuarta etapa se desarrolla desde el año 2005 a la actualidad. ${ }^{58}$ El inicio de esta etapa se fija en el año de la dictación por la Corte Interamericana de Derechos Humanos del fallo Almonacid A rellano vs. Chile, ${ }^{59}$ que impuso a los tribunales de justicia nacionales, entre otras cuestiones: el control de convencionalidad.

posterior, condiciona a la norma nueva interna, en atención a que la Convención de Viena sobre Derechos de los Tratados no permite invocar el Derecho interno como justificación de incumplimiento del tratado (artículo 27), como también, los principios generales del Derecho Internacional de aplicación de buena fe en los tratados internacionales; mientras no se determine internacionalmente su inaplicabilidad obligan al Estado que lo suscribió, sin perjuicio de los derechos de éste en cuanto a desahuciar el tratado conforme a las normas de derecho internacional o del propio tratado si fuese del caso".

58 Nota del autor: la revisión de jurisprudencia se extiende hasta el 31 de diciembre de 2007.

59 La sentencia de la Corte Interamericana de Derechos Humanos, en adelante la Corte Interamericana, se originó en la demanda presentada el 11 de julio de 2005 por la Comisión Interamericana de Derechos, en adelante la Comisión, contra el Estado de Chile, la que a su vez se originó en la denuncia número 12.057, recibida en la Secretaría de la Comisión el 15 de septiembre de 1998. La Comisión presentó la demanda en este caso con el objeto de que la Corte Interamericana decidiera si el Estado de Chile violó los derechos consagrados en los artículos 8 (Garantías Judiciales) y 25 (Protección Judicial) de la Convención Americana, en adelante la Convención, en relación con la obligación establecida en el artículo 1.1 (Obligación de Respetar los Derechos) de la misma, en perjuicio de los familiares del señor Luís Alfredo Almonacid A rellano. A simismo, la Comisión solicitó a la Corte que declare Chile incumplió con la obligación emanada del artículo 2 (Deber de adoptar disposiciones de derecho interno) de la Convención. Los hechos expuestos por la Comisión en la demanda se refieren a la presunta falta de investigación y sanción de los responsables de la ejecución extrajudicial del señor Almonacid Arellano, a partir de la aplicación del Decreto Ley 2.191, ley de amnistía, así como a la supuesta falta de reparación adecuada a favor de sus familiares. Además, la Comisión solicitó a la Corte Interamericana que, de conformidad con el artículo 63.1 de la Convención, ordene al Estado de Chile que adopte determinadas medidas de reparación indicadas en la demanda. Por la unanimidad, la Corte Interamericana declaró que el Estado de Chile incumplió sus obligaciones derivadas de los artículos 1.1 y 2 de la Convención A mericana sobre Derechos Humanos, y violó los derechos consagrados en los artículos 8.1 y 25 de dicho tratado, en perjuicio de la señora Elvira del Rosario Gómez Olivares y de sus hijos. Al pretender amnistiar a los responsables de delitos de lesa humanidad, el Decreto Ley 2.191 es incompatible con la Convención Americana y, por tanto, carece de efectos jurídicos, a la luz de dicho tratado. Dispuso la Corte Interamericana, que el Estado debe asegurarse que el Decreto Ley 2191 no siga representando un obstáculo para la continuación de las investigaciones de la ejecución extrajudicial del señor Almonacid A rellano y para la identificación y, en su caso, el castigo de los responsables; como así tampoco siga representando un obstáculo para la investigación, juzgamiento y, en su caso, sanción de los responsables de otras violaciones similares acontecidas en Chile. 
Los casos que se refirieron especialmente a la jerarquía de los tratados de derechos humanos se analizarán a continuación.

\section{A. Caso González Sáez /INP.}

La Corte de A pelaciones de Santiago, resolvió en el caso González Sáez C/ INP, un recurso de apelación. ${ }^{60}$ La resolución de la Corte de A pelaciones mandó indemnizar a los trabajadores que sufrieron un cambio unilateral en su calidad jurídica de obreros, siendo privados de sus empleos en dicha calidad, para denominarlos luego empleados públicos, por razones de política económica, desconociéndoles así un derecho fundamental garantizado.

Dijo la Corte de A pelaciones que la fuente de la responsabilidad civil, tratándose de una violación a los derechos humanos, está en normas y principios de Derecho Internacional de los Derechos Humanos.

Con respecto a la jerarquía de los tratados internacionales el fallo, redactado por el abogado integrante Hugo Llanos M ansilla, señaló expresamente su rango constitucional en el considerando № 7: "Que, en 1989, se agregó el siguiente inciso segundo al artículo 5o de la Constitución Política de la República: El ejercicio de la soberanía reconoce, como limitación el respeto a los derechos esenciales que emanan de la naturaleza humana. Es deber de los órganos del Estado respetar y promover tales derechos, garantizados por esta Constitución, así como por los tratados internacionales ratificados por Chile y que se encuentren vigentes. El artículo 5o le otorga así, rango constitucional a los tratados que garantizan el respeto a los derechos humanos, concediéndoles una jerarquía mayor que a los demás tratados internacionales, en cuanto regulan los derechos esenciales que emanan de la naturaleza humana".

\section{B. Casos sobre deudas previsionales}

La sentencia de la Corte Suprema de 9 de mayo de 2005, recaída en la apelación del recurso de amparo interpuesto a favor de Wilfredo Antilef Sanhueza, caso Antilef Sanhueza, confirmó la tesis sostenida por este tribunal desde 2004, aunque de manera vacilante, en orden a que el apremio decretado, arresto, constituye una amenaza ilegítima a la libertad personal de la recurrente, ya que el pago compulsivo de una cotización previsional deriva de una actuación que importa una prisión por deuda que en el ordenamiento jurídico nacional está proscrito, en atención a lo dispuesto en el artículo 7 № 7 del Pacto de San José de Costa Rica, en relación a lo establecido en el artículo 5으 de la Constitución Política de la República. ${ }^{61}$

En cuanto a la jerarquía de los tratados, la sentencia en comento reconoció su jerarquía supralegal al hacer primar lo previsto en el artículo 7 № 7 del Pacto de San

60 Corte de A pelaciones de Santiago. González Sáez C/ INP, (2006).

${ }_{61}$ Corte Suprema. Wilfredo Antilef Sanhueza con Juez Titular PrimerJuzgado del Trabajo San Miguel(2005). 
José de Costa Rica sobre la ley 17.322, cuando señala: "Vistos: A tendido el mérito de los antecedentes y estimándose que el apremio decretado constituye una amenaza ilegítima a la libertad personal de la recurrente, ya que el pago compulsivo de una cotización previsional deriva de una actuación que importa una prisión por deuda que en nuestro sistema jurídico está proscrito, en atención a lo dispuesto en el artículo 70, № 7 del Pacto de San José de Costa Rica, en relación a lo establecido en el artículo 5o de la Constitución Política de la República, se revoca la resolución apelada de dos de mayo del año en curso, escrita de fojas 8 a 10 y, en su lugar se declara que se acoge el recurso de amparo interpuesto a fojas 1, en favor de Wilfredo Antilef Sanhueza, debiendo dejarse sin efecto la orden de arresto despachada en su contra para el cobro de cotizaciones previsionales".

El 30 de mayo de 2005, la Corte de Apelaciones de Santiago resolvió sobre el recurso de amparo interpuesto a favor de Hugo Iturrieta Núñez, caso Iturrieta, señalando que el arresto decretado por el no pago de deudas previsionales no constituye prisión por deuda, que los tratados internacionales son "ley para la República", rechazando en consecuencia el recurso incoado.$^{62}$ La comentada decisión fue acordada con el voto en contra del abogado integrante Hugo Llanos $M$ ansilla quien fue de la opinión de acoger el recurso de amparo, resolviendo, como en casos anteriores, con fundamento en lo dispuesto por los tratados internacionales, en orden a concederles rango constitucional: "1‥ Que, al inciso 2 del artículo 5o de la Constitución Política de la

62 Corte de Apelaciones de Santiago. Hugo Iturrieta Núñez con Juez Segundo Juzgado de Letras del Trabajo de Santiago, (2005). Esto según lo señalan los considerandos Nos 3ㅇ a 60: “3‥ Que para los efectos de resolver el presente recurso es conveniente, en primer lugar, poner de manifiesto el carácter obligatorio de la norma jurídica aludida para los tribunales nacionales, atendido que dicho cuerpo de derecho internacional es ley en el territorio nacional en virtud de su ratificación parlamentaria y posterior promulgación. 4․ Que aún cuando es evidente que el apremio de arresto que motiva el presente recurso de amparo es consecuencia de la falta de pago de cotizaciones previsionales, y que de producirse su solución la medida de apremio que se cuestiona deberá ser dejada sin efecto por el tribunal a cargo del procedimiento de ejecución, ello no implica que la situación en cuestión deba tenerse como incumplimiento civil y que el arresto ordenado contradiga la prohibición, de prisión por deudas invocada. En efecto, la cantidad adeudada no deriva de alguna relación de derecho privado generadora de obligaciones de naturaleza patrimonial, en las que ciertamente es inaceptable la prisión en el evento de no haber tenido lugar el pago, sino que deviene del incumplimiento de la función pública, legal e imperativa asignada por el D.L. 3.500 a los empleadores, y que consiste en la recaudación de las cotizaciones y su entero en la entidad correspondiente elegida por el trabajador a objeto de obtener la finalidad de asegurar que todos estos coticen en el sistema previsional. 50. Que atendida la naturaleza jurídica del acto encomendado, la que no es excepción en el ordenamiento nacional si se tiene presente la función de recaudar tributos de diversa naturaleza y entre otros casos el sistema de concesiones de servicios públicos y algunos actos de fiscalización, no es posible aceptar para estos hechos la referida limitación a la potestad del Estado, por cuanto, como se ha razonado, lo impago no es consecuencia del incumplimiento de obligaciones de índole civil cual es la previsión del artículo XXV de la Declaración Americana de los Derechos y Deberes del Hombre, sino que de la omisión de enterar dineros ajenos que nunca ingresaron al patrimonio del empleador y que continúan siendo de dominio de los trabajadores; hecho que, además y porque la omisión de enterar no es deuda, tal apropiación ha dado lugar al tipo penal del artículo 19 inciso final del citado D.L. 3.500". En el mismo sentido fue rechazado el recurso de amparo interpuesto ante la Corte de A pelaciones de Santiago a favor de Christian Mueller Maturana. Corte de A pelaciones de Santiago, Christian Mueller Maturana con (2003). 
República que se refiere al ejercicio de la soberanía por el pueblo, se agregó, en 1989, la siguiente frase: «...Es deber de los órganos del Estado respetar y promover tales derechos, garantizados por esta Constitución, así como por los tratados internacionales ratificados por Chile y que se encuentren vigentes». El artículo 5o le otorga así, rango constitucional a los tratados que garantizan el respeto a los derechos humanos, concediéndoles una jerarquía mayor que a los demás tratados internacionales". Concluye en el considerando № 3: "Que, de lo expuesto, cabe concluir que el Pacto de San José de Costa Rica tiene una jerarquía superior a la ley № 17.322 y que, por lo demás, al haber sido esta ley publicada en 1970, fue derogada por el Pacto, cuya publicación, en el Diario Oficial, fue posterior: el 5 de enero de 1991".

Por su parte, la Corte Suprema en el mismo caso Iturrieta, a diferencia de los casos anteriores en los que consideró proscrita la prisión por deuda en virtud de lo dispuesto en los tratados internacionales, confirmó la sentencia apelada rechazando el recurso de amparo interpuesto. ${ }^{63}$ Sin embargo, esta decisión fue acordada contra el voto del Ministro Cury, quien estuvo por revocar la resolución en alzada y acoger el recurso de amparo, estimando que el apremio decretado constituye una amenaza ilegítima a la libertad personal del recurrente ya que el pago compulsivo de una cotización previsional deriva de una actuación que importa una prisión por deuda que en el sistema jurídico está proscrita, en atención a lo dispuesto en el artículo 7 № 7 del Pacto de San José de Costa Rica en relación a lo establecido en el artículo 50 de la Constitución Política de la República. En el caso Mueller, la Corte Suprema también confirmó la sentencia apelada, rechazando el recurso de amparo interpuesto; sin embargo fueron dos los votos disidentes, del Ministro Cury y del abogado integrante Emilio Pfeffer, quienes expusieron idénticos fundamentos que en el voto disidente del caso Iturrieta. ${ }^{64}$

En el año 2006, la Corte de A pelaciones de Santiago resolvió rechazando el recurso de amparo interpuesto a favor de Julio Pérez Fuenzalida, caso Pérez Fuenzalida, considerando que el arresto por el no pago de las deudas previsionales no constituye prisión por deuda. ${ }^{65} \mathrm{~A}$ sí en los considerandos Nos 30 y 4 o expresan: "3o. Que, por lo expresado, no concurre ninguno de los supuestos que hacen procedente el recurso de amparo, toda vez que la orden de arresto decretada ha sido expedida por autoridad facultada para ello, ya que en la especie se trata de un apremio legítimo expresamente consagrado en la ley (artículo 12 de la ley $N$ o 17.322), de modo que la referida orden se ajusta plenamente a la Constitución Política de la República y no ha vulnerado ningún derecho garantido por ésta. 4‥ Que, no puede estimarse que la retención de las cotizaciones a los trabajadores y su no pago a la entidad previsional correspondiente constituya un supuesto propio de una prisión por deudas de aquellas que proscribe la Convención A mericana de Derechos Humanos, toda vez que en la especie se

63 Corte Suprema. Hugo Iturrieta Núñez con Juez Segundo Juzgado de Letras del Trabajo de Santiago (2005).

64 Corte Suprema. Christian Mueller Maturana con (2005).

65 Corte de A pelaciones de Santiago. Julio Pérez Fuenzalida con Juzgados de Letras del Trabajo de Santiago (2006). 
trata de retenciones efectuadas a los sueldos de los trabajadores con esa precisa finalidad por el amparado en su condición de representante legal de la empresa empleadora, por lo que corresponde desestimar la acción constitucional intentada". Esta sentencia fue acordada con el voto en contra del abogado integrante, Hugo Llanos M ansilla, quien como en los casos anteriores resolvió considerando el rango constitucional de los tratados de derechos humanos, particularmente el Pacto de San José de Costa Rica que proscribe la prisión por deuda, debiendo, a su juicio, aplicarse preferentemente sobre la ley 17.322 .

\section{Casos sobre aplicación de la ley de amnistía}

En el año 2005, la Corte de A pelaciones de San M iguel, dictó sentencia en el caso Cerro Chena de San Bernardo y continuó la doctrina inaugurada en el caso Poblete Córdova y mantenida en el caso Sandoval Rodríguez, inaplicando la ley de amnistía. ${ }^{66}$ En este caso, al igual que los mencionados, la Corte de A pelaciones estimó que durante la ocurrencia de los hechos constitutivos de delitos el país se encontraba en estado de guerra y que por tanto tenían pleno vigor los Convenios de Ginebra de 1949, en los cuales se establece que ninguna de las partes contratantes tendrá la facultad para exonerarse a sí misma o exonerar a otra parte de responsabilidades incurridas por ella o por otra, a causa de aquellas graves infracciones, siendo en consecuencia inaplicable el decreto ley de amnistía 2.191, declarando que no es proced ente sobreseer definitivamente a Víctor Pinto Pérez, por amnistía, debiendo el tribunal a quo proseguir con la tramitación de la causa.

En relación con la jerarquía de los tratados sobre derechos humanos el fallo en cuestión establece la superior jerarquía de los tratados de derechos humanos sobre la norma interna, en el considerando № 15 cuando dice: "Que, a fin de cuentas, la Junta de Gobierno (esto es el Estado chileno) al ejercer el poder legislativo y amnistiar ciertos delitos amparando los agravios cometidos contra personas determinadas y procurando la impunidad de sus autores, no pudo soberanamente sobrepasar sus límites y contrariar el orden nacional y universal ya consignado preeminente en materia de derechos humanos, ni menos burlar artificiosamente los Tratados aludidos, suscritos y ratificados por Chile, incumpliendo las obligaciones asumidas, sin previa denuncia, pues esto último constituye además una inobsenvancia a la buena fe que le era exigi-

66 Corte de A pelaciones. Ramón Luis Vivanco Díaz, A diel Monsalves Martínez, Manuel Zacarías González Vargas, José Leningrado Morales Álvarez, Arturo Koyck Fredes, Joel Guillermo Silva Oliva, Roberto Segundo Á vila Márquez, Alfredo A cevedo Pereira, Raúl Humberto Castro Caldera, Pedro Enrique Oyarzún Zamorano y Hernán Elías Chamorro Monardes con Víctor Raúl Pinto Pérez (2005). Los sucesos materia del encausamiento consisten básicamente en que las víctimas, trabajadores de la Maestranza de Ferrocarriles de San Bernardo, fueron privados de libertad y recluidos en un centro de prisioneros del Cerro Chena, a cargo de personal de las Fuerzas Armadas. La Sra. M inistro de Fuero sobreseyó total y definitivamente en la causa al inculpado, por la concurrencia de la causal de extinción de la responsabilidad penal prevista en el artículo 93 № 3 del Código Penal, esto es la amnistía otorgada por el decreto ley № 2191, de 18 de abril de 1978. 
ble, como al principio pacta sunt servanda, reglados en los artículos 26 y 27 de la Convención de Viena sobre el Derecho de los Tratados de 1969".

En el año 2005, en el caso Vidal Riquelme ${ }^{67}$ el Ministro de Fuero, Jorge Zepeda A rancibia, señaló en el considerando $\mathrm{N}^{\circ} 7$ que los delitos de secuestro calificado y homicidio calificado, objeto del caso, son delitos de lesa humanidad. ${ }^{68}$

En lo que respecta a la jerarquía de los tratados de derechos humanos el fallo señaló en el considerando $N^{\circ}$ 9: "A demás, los principios internacionales referidos, los convenios, pactos y tratados en que se reconocen los derechos humanos y las garantías a nivel de tribunales nacionales, gozan de primacía constitucional, cuya consecuencia -conforme a una interpretación progresiva y finalista de la Constitución- es que prevalecen sobre la legislación interna, toda vez que se entiende que la prefieren, perfeccionan y complementan. Siendo, por lo mismo, tal normativa invocable por todos los individuos, atendido el compromiso moral y jurídico del Estado ante la comunidad internacional, de respetarlos, promoverlos y garantizarlos".

Por otro lado, el M inistro Zepeda A rancibia concluyó que los delitos de lesa humanidad, por disposición del Derecho Internacional Humanitario, son inamnistiables e imprescriptibles. A gregó, que al tratarse de este tipo de delitos rigen los Principios del Derecho Internacional, como categoría de norma de Derecho Internacional General (ius cogens), conforme al acervo dogmático y convencional universal y de la aceptación en la práctica de los tribunales nacionales miembros de la Organización de las Naciones Unidas, además de los tribunales internacionales con jurisdicción respecto a crímenes de lesa humanidad. En la misma línea en el considerando $N^{\circ} 41$ expresa: "Que, lo anterior permite concluir que hay entonces una prevalencia de la norma internacional de Derecho Internacional General, que determina que son incompatibles con ésta las leyes de amnistía y de prescripción invocadas respecto de los hechos delictivos establecidos en autos". Invoca para fundamentar tal afirmación la jurisprudencia de la Corte Interamericana de Derechos Humanos, que ha reconocido la incompatibilidad de las leyes de amnistía con la Convención A mericana sobre Derechos Humanos, en el caso conocido como Barrios Altos vs. Perú, de fecha 14 de marzo de 2001.

En cuanto a la procedencia de las acciones civiles reparatorias contra el Fisco de Chile, el Ministro Zepeda A rancibia señaló en el considerando $N^{\circ} 65$ : "Que, en consecuencia, no conformándose las disposiciones invocadas por el Fisco de Chile, para eximirse de responsabilidad, a la batería normativa internacional que se ha analizado

67 Ministro de Fuero. Luis Vidal Riquelme Norambuena con Claudio Abdón Lecaros Carrasco; José Basilio Muñoz Pozo; Omar Antonio Mella Lillo (2005).

68 En el considerando $\mathrm{N}^{\circ} 8$ argumenta sobre la misma idea: “Octavo: Que, atendidas las circunstancias o condiciones exteriores en que se materializaron estos delitos o elementos contextuales de éstos, entendido lo anterior como el marco de hecho subjetivo en que se desarrollaron las conductas criminales que las diferencian de los delitos comunes, determinan que se está en este caso en presencia de lo que la conciencia jurídica internacional ha dado en llamar crímenes de naturaleza de lesa humanidad". 
con ocasión del crimen de lesa humanidad, cometido en contra de la víctima Vial del Carmen Riquelme Ibáñez, plenamente aplicables por este aspecto, y siendo ellas prevalentes sobre el Derecho interno, se rechaza la excepción de incompetencia absoluta formulada por el Fisco de Chile, por resultar inatinente en la especie y por este aspecto la disposición del artículo 10 del Código de Procedimiento Penal, como se ha razonado en razón de la categoría internacional que tiene el delito". A nte el conflicto entre la norma interna y la norma internacional, el M inistro resolvió a favor de la internacional reconociendo su mayor jerarquía, lo que se expresa en el considerando $N^{\circ} 67:$ "Que, del mismo modo, resultan inatinentes las normas del Derecho Interno previstas en el Código Civil, sobre prescripción de las acciones civiles comunes de indemnización de perjuicios, invocadas por el Fisco de Chile, al estar en contradicción con las normas del Derecho Internacional de los Derechos Humanos, que protegen el derecho de recibir la reparación correspondiente a las víctimas y familiares de éstas, estatuto normativo internacional reconocido por Chile".

En otro caso, del año 2006, la Corte de A pelaciones de Santiago rechazó la prescripción de la acción penal originada en el fusilamiento y ocultamiento de miembros del Dispositivo de Seguridad y A sesores de la Presidencia de la República, por tratarse de delitos de lesa humanidad, con participación estatal. ${ }^{69}$ La Corte de A pelaciones, además de concluir que los hechos investigados forman parte y son constitutivos de un delito de lesa humanidad, remató señalando que es imprescriptible como categoría de norma de Derecho Internacional General, incorporando la noción del ius cogens. Esto último implica la imprescriptibilidad de los delitos de lesa humanidad, como norma vinculante para Chile, no sólo por estar prevista en tratados internacionales ratificados por Chile y vigentes, como es el caso de los Convenios de Ginebra de 1949, sino que incluso por estar contemplada en aquellos tratados internacionales aún no ratificados por Chile, como es el caso de Convención sobre la Imprescriptibilidad de los Crímenes de Guerra y de los Crímenes de Lesa Humanidad, adoptada y abierta a la firma, ratificación y adhesión por la Asamblea General en su resolución № 2391 (XXIII), de 26 de noviembre de $1968 .{ }^{70}$

69 Corte de A pelaciones de Santiago. no consignado con Fernando Remigio Burgos Díaz; Sergio Antonio M edina Salazar; Isidro Custodio Durán M uñoz; José Jaime Darrigrandi Marquez (2006). Ello conforme a normas del Derecho Internacional, según lo contempla el considerando № 3 de la sentencia redactada por el ministro Jorge Zepeda, que dice: “Que, en consecuencia, dado el carácter complejo del crimen que se inicia con el secuestro de las personas hasta hoy desaparecidas y su vinculación con la conducta descrita en la acusación de autos, ello determina que el delito por el cual se ha acusado, es de una naturaleza especial con un grado mayor de inmoralidad en su ejecución que lo distingue de un delito común, de tal modo que al relacionarse con un ataque generalizado y sistemático en contra de parte de la población civil, debe ser perseguido penalmente como delito de lesa humanidad".

70 El fallo en comento en el considerando № 11 señala: "Que, así entonces, si bien el instrumento internacional anterior aunque suscrito no ha sido ratificado por Chile, la imprescriptibilidad de los crímenes de lesa humanidad surge en la actualidad como categoría de norma de Derecho Internacional General (ius cogens), esto es, conforme al acervo dogmático y convencional universal y de la aceptación en la práctica judicial de los tribunales nacionales partícipes de la Organización de las Naciones Unidas, además de los tribunales internacionales con jurisdicción respecto de crímenes de lesa humanidad". 
En el considerando № 13 el fallo dispone que las normas del ius cogens se incorporan al ordenamiento interno por la vía del artículo 5 o inciso segundo de la Constitución: "Que, en cuanto a la obligatoriedad de las normas ius cogens respecto de la imprescriptibilidad aludida, en nuestro ordenamiento jurídico es la Constitución la que la reconoce en el artículo 50 inciso segundo y permite la posibilidad de incorporarlo". A bunda esta sentencia en la idea de la imprescriptibilidad de los delitos de lesa humanidad, señalando en el considerando № 14: "Que, así, la Carta Fundamental siguiendo el mecanismo propio para incorporar el Derecho Internacional al Nacional o interno, permitió el reconocimiento de la imprescriptibilidad de los crímenes de lesa humanidad, introduciendo un aseguramiento objetivo y expreso de los derechos humanos".

Con respecto a los tratad os internacionales la sentencia les reconoce fuerza constitucional material en el considerando № 15: "Que en relación con la aseveración anterior, es decir, de la obligatoriedad de las normas ius cogens o Principios Generales del Derecho Internacional, que determinan la imprescriptibilidad de los delitos de lesa humanidad por cuanto, el reconocimiento de las conductas delictivas en sí lo ha sido claramente, vía tratado expreso según se ha expuesto precedentemente, por medio de los Convenios de Ginebra de 1949, sobre derecho humanitario, ratificados por Chile en el año 1951 y que constituyen ley de la República, con fuerza constitucional material debe tenerse presente que de acuerdo al artículo 5o, inciso segundo, de la Constitución, los derechos asegurados en un tratado se incorporan al ordenamiento jurídico nacional o interno vigente, no pudiendo el Estado y, por lo tanto, ninguno de sus órganos desconocerlos".

Por otra parte, la sentencia le reconoce a las normas del derecho internacional, particularmente las normas del ius cogens, preeminencia sobre las disposiciones internas, en el considerando № 16, al decir: "Que el ius cogens o Principios Generales del Derecho Internacional se integran a tal normatividad, si se razona que, en su oportunidad, el poder constituyente incorporó como tratado la Convención de Viena sobre los Derechos de los Tratados, ratificado por Chile el 9 de abril de 1981, promulgado por Decreto Supremo № 381 de 1981, reconociendo Chile la primacía del derecho internacional sobre el derecho interno, no pudiendo invocar ninguna razón legítima para atropellar el cumplimiento de buena fe de las obligaciones contraídas artículo 26 de dicha convención (sic), apoyando con ello decididamente lo dispuesto en el artículo 27 de la misma, (... ) Además, en el punto que nos ocupa que el ius cogens se integra a la normatividad propia de los tratados la incorporación de dicha Convención de Viena sobre los Derechos de los Tratados (...). Es decir, vía tal tratado se reconoce expresamente el valor del principio ius cogens en general, el que se comprende, entonces, como una norma de Derecho Internacional General que debe ser respetada con la misma decisión que tiene un tratado ratificado por Chile, no sólo por la especial forma en que puede ser modificado, sino como se dijo anteriormente porque su entidad es tal que el propio artículo 53 de la Convención determina que: es nulo todo tratado que, en el momento de su celebración, esté en oposición con una norma imperativa de Derecho Internacional General". 
En la parte resolutiva del fallo, la Corte de A pelaciones hizo mención expresa a la disposición 250 del Código Procesal Penal, sobre sobreseimiento definitivo, norma que de alguna manera reconoce a los tratad os internacionales mayor jerarquía que las propias disposiciones legales internas, particularmente en relación con el decreto ley 2191: "El juez de garantía decretará el sobreseimiento definitivo: inciso final: El juez no podrá dictar sobreseimiento definitivo respecto de los delitos que, conforme a los tratados internacionales ratificados por Chile y que se encuentren vigentes, sean imprescriptibles o no puedan ser amnistiados, salvo en los casos de los números $1^{\circ}$ y y $2^{\circ}$ del artículo 93 del Código Penal".

En julio de 2006, la Corte de A pelaciones de Santiago falló en la apelación del caso Carlos Contreras M aluje, por el cual se estableció que el secuestro calificado establecido en este proceso es un delito permanente. ${ }^{71}$ En consecuencia, el tribunal sentenció que se hace imposible contabilizar el término de prescripción de la acción penal, o concluir que el hecho delictivo está afecto a la normativa de la amnistía, pues, por un lado, no ha quedado superado el último acto del plazo de la prescripción que señala el artículo 95 del Código Penal, por el otro, que se encuadre a la amnistía que se invoca por las defensas.

El fallo en cuestión fue acordado con una prevención del ministro Jorge Zepeda, quien además consideró el delito de secuestro permanente como delito de lesa humanidad y en consecuencia indemnizable. En cuanto a la jerarquía de los tratados el ministro Zepeda expresó en el considerando № 6 la jerarquía constitucional de los tratados de derechos humanos: "Que, además, los principios internacionales referidos, los convenios, pactos y tratados en que se reconocen los derechos humanos y las garantías a nivel de tribunales nacionales, gozan de primacía constitucional, cuya consecuencia conforme a una interpretación progresiva y finalista de la Constitución es que prevalecen sobre la legislación interna, toda vez que se entiende que la prefieren, perfeccionan y complementan. Siendo, por lo mismo, tal normativa invocable por todos los individuos, atendido el compromiso moral y jurídico del Estado ante la comunidad internacional, de respetarlos, promoverlos y garantizarlos".

Por otra parte, en sentencia recaída en el caso Lago Ranco, la Corte de A pelaciones de Santiago estimó que los ilícitos de secuestros calificados materia de la acusación constituyen delitos de lesa humanidad, que el país se encontraba en estado de guerra y por lo tanto son aplicables al caso las normas del Derecho Internacional Humanitario, entre otros los Convenios de Ginebra de 1949, lo que determina que los delitos en cuestión sean imprescriptibles. ${ }^{72}$

71 Corte de A pelaciones de Santiago. Contreras A burto, Luis / Ruiz Bunger, Freddy; Saavedra Loyola, Juan; Cobos Manríquez, Jorge; Guimpert Corvalán, Daniel; Muñoz Gamboa, Manuel; Palma Ramírez, César; Sáez Mardones, Alejandro (2006).

72 Corte de A pelaciones de Santiago. Estado de Chile; M iriam Luz Ancacura Pafián; M aría Ester Hernández Martínez; con Sergio Héctor Rivera Bozzo (2006), 8 de noviembre de 2006. En el año 2007, en el caso Urrutia Galaz, el voto en contra del abogado integrante de la Corte de A pelaciones de Santiago, Nelson 
La sentencia redactada por el ministro Nelson Pozo es explícita en cuanto a reconocer a los tratados rango constitucional, así lo expresa en varios considerandos. En el № 5: "Que, de otra parte, como se ha reiterado en numerosas sentencias de Tribunales de la República, el artículo 5o inciso 2o de la Constitución Política, ha venido a reconocer y relevar el valor y primacía de los tratados y convenios internacionales de derechos humanos suscritos por Chile y vigentes; los cuales ya antes tenían ese valor, preeminencia y jerarquía". En el considerando № 21: "Que, en 1989, se agregó el siguiente inciso segundo al artículo 5o de la Constitución Política de la República: "El ejercicio de la soberanía reconoce, como limitación el respeto a los derechos esenciales que emanan de la naturaleza humana. Es deber de los órganos del Estado respetar y promover tales derechos, garantizados por esta Constitución, así como por los tratados internacionales ratificados por Chile y que se encuentren vigentes. El artículo 5 o le otorga así, rango constitucional a los tratados que garantizan el respeto a los derechos humanos, concediéndoles una jerarquía mayor que a los demás tratados internacionales, en cuanto regulan los derechos esenciales que emanan de la naturaleza humana". Asimismo en el considerando № 23 ratificó el rango constitucional de los tratados sobre derechos humanos en los siguientes términos: "Que, porúltimo, la enmienda al artículo 5o de nuestra Carta Fundamental tuvo por objeto reforzar el avance de los derechos humanos, al establecer "como deber de los órganos del Estado, respetar y promover tales derechos" e igualar los derechos humanos contenidos en la Carta Fundamental con los incluidos en los tratados internacionales".

La Corte Suprema con fecha 13 de marzo de 2007, conociendo de un recurso de casación en el fondo por el homicidio calificado de M anuel Tomás Rojas Fuentes, acaecido en la Guarnición Chena ${ }^{73}$ sostuvo que los delitos perpetrados en la persona de Rojas Fuentes fueron cometidos en estado de guerra interna, que se trataba de un

Pozo Silva, estuvo por revocar la sentencia en alzada y condenar a los encartados como autores del delito de homicidio calificado de David Urrutia Galaz y acceder a la acción civil interpuesta, a fin de que se repare en el aspecto civil, en virtud de la responsabilidad civil del Estado, con similares fundamentos que aquellos planteados en el caso Lago Ranco. En cuanto a la jerarquía de los tratados, reiteró en el considerando № 7 lo sostenido en el considerando № 5 del caso Lago Ranco. A su vez reiteró en el № 15: “Que, en 1989, se agregó el siguiente inciso segundo al artículo 5o de la Constitución Política de la República: El ejercicio de la soberanía reconoce, como limitación el respeto a los derechos esenciales que emanan de la naturaleza humana. Es deber de los órganos del Estado respetar y promover tales derechos, garantizados por esta Constitución, así como por los tratados internacionales ratificados por Chile y que se encuentren vigentes. El artículo 5 o le otorga así, rango constitucional a los tratados que garantizan el respeto a los derechos humanos, concediéndoles una jerarquía mayor que a los demás tratados internacionales, en cuanto regulan los derechos esenciales que emanan de la naturaleza humana". En el considerando № 17 ratificó la idea del rango constitucional al expresar: "Que, por último, la enmienda al artículo 50 de nuestra Carta Fundamental tuvo por objeto reforzar el avance de los derechos humanos, al establecer como deber de los órganos del Estado, respetar y promover tales derechos e igualar los derechos humanos contenidos en la Carta Fundamental con los incluidos en los tratados internacionales". Corte de A pelaciones de Santiago. Mario Urrutia Villa con Freddy Enrique Ruiz Bunger; Juan Francisco Saavedra Loyola; César Luis Palma Ramírez; Otto Silvio Trujillo Miranda; Eduardo Enrique Cartagena (2007).

73 Corte Suprema. No se consigna con Víctor Raúl Pinto Pérez (2007). 
delito de lesa humanidad, todo lo cual hace plenamente aplicables las disposiciones de los Convenios de Ginebra, vigentes al perpetrarse tales delitos, y por lo tanto respecto ellos no procede la amnistía.

En relación con la jerarquía de los tratados, el fallo se refirió al conflicto normativo entre la ley de amnistía y los tratados internacionales, estableciendo que el mismo se resuelve prefiriendo la aplicación de los tratados. Así lo expresó el considerando $\mathrm{N}^{\circ} 23$ : "Que, desde luego, en virtud del ejercicio de su soberanía, nuestra Nación puede amnistiar las infracciones penales que se realicen y que estén sometidas a su potestad. Empero si ha limitado su propio poder respecto de ciertos injustos en un compromiso internacional, como en el evento en examen, no puede soberanamente sobrepasar dicho límite autoimpuesto y contrariar, de ese modo, el orden nacional y universal ni menos burlar los tantas veces mencionados Convenios, suscritos y ratificados por Chile, incumpliendo las obligaciones asumidas, sin previa denuncia de aquellos, dado que no es justificable que vinculado mediante ellos, se trate luego de eludir su acatamiento invocando la legislación nacional ordinaria". En el mismo sentido el considerando $\mathrm{N}^{\circ}$ 25: "Que, por ende, el decreto ley № 2.191, de mil novecientos setenta y ocho, debe ser interpretado en un sentido conforme con los Convenios de Ginebra, por lo que es inexequible respecto a las contravenciones graves contra los derechos esenciales determinados en ellos y cometidos en nuestro país durante su vigencia". Esta idea se reitera al señalar en el considerando $N^{\circ} 38:$ "Que la obligación estatal que dimana de la Constitución, de los Tratados Internacionales sobre Derechos Humanos y de los Principios Generales de Derecho Internacional Humanitario, existía bajo nuestra Carta Fundamental de mil novecientos veinticinco, pues Chile al igual que hoy era un Estado Constitucional de Derecho, y le era exigible la congruencia de aquélla con los aludidos acuerdos multilaterales y axiomas. Por lo que el legislador no tiene atribución alguna para modificar por ley un acuerdo internacional y si bien podría dictarla, prescribiendo disposiciones contrarias a éste o que hiciesen imposible su cumplimiento, ese acto del órgano legislativo comportaría una contravención al ordenamiento internacional. No puede ser de otra manera, en especial respecto de los tratados en materia de derechos humanos, ya que "éstos tienen una naturaleza distinta de la ley, en la medida en que no son actos jurídicos unilaterales, sino actos jurídicos bi o multilaterales en que intervienen las voluntades de diversos Estados. Además, estos tratados se constituyen no en beneficio de los Estados parte sino en resguardo de la dignidad y los derechos inherentes al ser humano por el sólo hecho de ser persona. Los Estados parte por tal reconocimiento constituyen una autolimitación a su soberanía, No pueden, por tanto, desvincularse unilateralmente de los tratados en materia de derechos humanos, sino de acuerdo al procedimiento establecido en ellos mismos (Humberto Nogueira Alcalá: "Constitución y Derecho Internacional de los Derechos Humanos, en Revista Chilena de Derecho, Facultad de Derecho, Pontificia Universidad Católica de Chile, volumen 20, Nos 2 y 3, tomo II, mayo diciembre de mil novecientos noventa y tres, página 887). Un acuerdo internacional, por ende, no puede dejar de aplicarse sino de conformidad con las normas de derecho internacional (Gaceta Jurídica, Nos 177 y 185, páginas 165 y 120, respectivamente)". 
Por otra parte, señaló la primacía constitucional de los tratados en el considerando $N^{\circ}$ 35: "Que también los principios internacionales referidos, los convenios, pactos y tratados en que se reconocen los derechos humanos y las garantías a nivel de tribunales nacionales, gozan de primacía constitucional, cuyo colofón de acuerdo a una interpretación progresiva y finalista de la Constitución es que prevalecen sobre la legislación interna, toda vez que se entiende que la prefieren, perfeccionan y complementan. Siendo, por lo mismo, tal normativa invocable por todos los individuos, atendido el compromiso moral y jurídico del Estado ante la comunidad internacional de respetarlos, promoverlos y garantizarlos".

El 23 de marzo de 2007, la Corte de A pelaciones resolvió el caso Muller, haciendo expresa mención al rango constitucional de los tratados de derechos humanos. En el presente caso Rudolph Muller y Sonia M uller entablaron demanda civil contra el Fisco de Chile y demanda penal a los responsables de la desaparición de Jorge Muller y su novia Carmen Bueno. ${ }^{74}$

Lo relevante de la sentencia recaída en este caso es la mención al fallo A Imonacid A rellano, el cual es citado en el considerando № 3: "Que la Corte Interamericana en el caso Almonacid A rellano y otros vs. Chile -sentencia de fecha 26 de septiembre de 2006-, que condenó al Estado chileno, sostuvo lo siguiente: «En efecto, por constituir un crimen de lesa humanidad, el delito cometido en contra del señor A Imonacid AreIlano, además de ser inamnistiable, es imprescriptible. Como se señaló en los párrafos 105 y 106 de esta sentencia, los crímenes de lesa humanidad van más allá de lo tolerable por la comunidad internacional y ofenden a la humanidad toda. El daño que tales crímenes ocasionan permanece vigente para la sociedad nacional y para la comunidad internacional, las que exigen la investigación y el castigo de los responsables. En este sentido, la Convención sobre la imprescriptibilidad de los crímenes de guerra y de los crímenes de lesa humanidad claramente afirmó que tales ilícitos internacionales «son imprescriptibles, cualquiera que sea la fecha en que se hayan cometido. «153. Que, aun cuando Chile no ha ratificado dicha Convención, esta Corte considera que la imprescriptibilidad de los crímenes de lesa humanidad surge como categoría de norma de Derecho Internacional General (ius cogens), que no nace con tal Convención sino que está reconocida en ella. Consecuentemente, Chile no puede dejar de cumplir esta norma imperativa»".

La sentencia incluso hizo mención al control de convencionalidad que impone la Corte Interamericana a los tribunales de justicia chilenos en el caso A Imonacid A rellano, así en el considerando № 26 señala: "Que, la Corte Interamericana, en el caso A Imonacid A rellano y otros vs. Chile, sostuvo lo siguiente: «124. La Corte es consciente que los jueces y tribunales internos están sujetos al imperio de la ley y, por ello, están obligados a aplicar las disposiciones vigentes en el ordenamiento jurídico. Pero

${ }_{74}$ Corte de A pelaciones de Santiago. Rudolph Muller Muller; Sonia Ida María Muller Silva; con Fisco de Chile (2007). 
cuando un Estado ha ratificado un tratado internacional como la Convención A mericana, sus jueces, como parte del aparato del Estado, también están sometidos a ella, lo que les obliga a velar porque los efectos de las disposiciones de la Convención no se vean mermadas por la aplicación de leyes contrarias a su objeto y fin, y que desde un inicio carecen de efectos jurídicos. En otras palabras, el Poder Judicial debe ejercer una especie de «control de convencionalidad» entre las normas jurídicas internas que aplican en los casos concretos y la Convención Americana sobre Derechos Humanos. En esta tarea, el Poder Judicial debe tener en cuenta no solamente el tratado, sino también la interpretación que del mismo ha hecho la Corte Interamericana, intérprete última de la Convención A mericana. «125. En esta misma línea de ideas, esta Corte ha establecido que usegún el derecho internacional las obligaciones que éste impone deben ser cumplidas de buena fe y no puede invocarse para su incumplimiento el derecho interno». Esta regla ha sido codificada en el artículo 27 de la Convención de Viena sobre el Derecho de los Tratados de 1969".

El fallo, además, hizo alusión a la jurisprudencia de la Corte Interamericana de Derechos Humanos en cuanto a la obligación del Estado de reparar cuando ha causado daño como consecuencia de un hecho ilícito imputable al mismo.

El considerando № 15 expresamente resuelve sobre el rango de los tratados de derechos humanos, atribuyéndoles rango constitucional: "Que, el artículo $5^{\circ}$ de nuestra Carta Fundamental le otorga así, rango constitucional a los tratados que garantizan el respeto a los derechos humanos, concediéndoles una jerarquía mayor que a los demás tratados internacionales, en cuanto regulan los derechos esenciales que emanan de la naturaleza humana". En el considerando № 16 del fallo los sentenciadores mencionaron a la historia de la reforma al artículo 50 en el año 1989, citando al profesor Francisco Cumplido, para así en el considerando № 17 ratificar la posición que reconoce a los tratados rango constitucional: "Que, de lo expuesto, se concluye que si los tratados de derechos humanos fueron incluidos en la modificación constitucional citada, se infiere que esos últimos necesariamente han de tener una mayor jerarquía en el ordenamiento jurídico nacional, que el resto de los tratados internacionales".

Finalmente en el caso Millalén, el ministro de la Corte de A pelaciones de Santiago, Jorge Zepeda A rancibia ${ }^{75}$ concurrió a la decisión de condena y previno que el delito de secuestro calificado es un delito de lesa humanidad. En consecuencia consideró que debe seguirse la doctrina sentada en el caso Sandoval Rodríguez, y que conforme a la legislación del derecho internacional público, independiente del carácter de delito permanente que tiene el secuestro calificado, debe reconocerse la existencia de la imprescriptibilidad de este tipo de crímenes, por tratarse de violaciones al Derecho Internacional Penal de los Derechos Humanos.

75 Sentencia Corte de A pelaciones de Santiago. Benito Millalén Sandoval con Augusto Pinochet Ugarte; Germán Víctor Fagalde Osorio; Mario Hernán Fagalde Osorio; Enrique Ferrier Valeze (2007). 
En el último caso de análisis y con respecto a la jerarquía de los tratados de derechos humanos, el previniente sostuvo que aquellos tienen aplicación preeminente e inmediata sobre la legislación nacional. Reiteró los considerandos relevantes del caso Sandoval y enfatizó de aquel: "2o. "Q Que, en consecuencia, el Estado de Chile se impuso, al suscribir y ratificar los citados Convenios, la obligación de garantizar la seguridad de las personas que pudieren tener participación en conflictos armados dentro de su territorio, especialmente si fueren detenidas, quedando vedadas las medidas tendientes a amparar los agravios cometidos contra personas determinadas o lograr la impunidad de sus autores, teniendo especialmente presente que los acuerdos internacionales deben cumplirse de buena fe. Y en cuanto el Pacto persigue garantizar los derechos esenciales que nacen de la naturaleza humana, tiene aplicación preeminente, puesto que esta Corte Suprema en reiteradas sentencias ha reconocido que la soberanía interna del Estado de Chile reconoce su límite en los derechos que emanan de la naturaleza humana; valores que son superiores a toda norma que puedan disponer las autoridades del Estado, incluido el propio Poder Constituyente, lo que impide sean desconocidos. (Considerandos 34 y 35 de la citada sentencia de la Excelentísima Corte Suprema)".

En definitiva, examinada la jurisprudencia de esta última etapa, se observa la tendencia de los tribunales superiores de justicia, ya sea en los fallos con decisión de mayoría o en los votos de minoría, a reconocer la preeminencia de la aplicación de los tratados de derechos humanos ante un conflicto normativo con la legislación interna. Las expresiones que dan cuenta de ello son los términos reiterados: "prevalencia", "preeminencia", "primacía". En casos puntuales como Lago Ranco y Urrutia Galaz se reconoce el rango constitucional a los tratados de derechos humanos. Por otro lado, en casos como M uller, se hace expresa mención a la mayor jerarquía de los tratados, respecto de la legislación interna, con base en lo resuelto por la Corte Interamericana de Derechos Humanos en el caso A Imonacid A rellano vs. Chile.

Todo lo anterior redundó en la no aplicación de la ley de amnistía por ser contraria al Derecho Internacional de los Derechos Humanos.

\section{CONCLUSIONES}

La Constitución como norma jurídica fundamental y fundante del ordenamiento jurídico es quien debe decidir la jerarquía que los tratados internacionales, pudiendo decidir que tengan jerarquía legal o supralegal, incluso la Constitución podría disponer resignar o compartir su primer escalón jerárquico con aquellos. Lamentablemente, como se ha señalado en este trabajo, la Constitución Política de la República de Chile no ha referido expresamente cuál es la jerarquía de los tratados, cuestión que deberá resolverse por vía interpretativa. Tal labor interpretativa le corresponde a todos los órganos del Estado, pero especialmente compete a los tribunales de justicia.

La Evolución Jurisprudencial en la materia permite distinguir a lo menos cuatro etapas diferenciadas. En la primera etapa de Evolución jurisprudencial, 1980-1989, los 
tribunales consideraron que los tratados tenían el mismo valor y jerarquía que la ley. Por otro lado, en esta etapa se consideró que aquellos pactos que habían sido promulgados pero no publicados no tenían vigencia interna, con fundamento nuevamente en la asimilación de los tratados a la ley.

En la segunda etapa de la Evolución Jurisprudencial, 1989-1994, las resoluciones judiciales recaídas lo fueron principalmente en torno a tres materias. La primera de ellas, casos sobre Ley de Cheques, puede concluirse que la jurisprudencia fue vacilante en orden a establecer la compatibilidad del artículo 44 de la Ley de Cuentas Corrientes Bancarias y Cheques con el artículo 7 № 7 del Pacto de San José de Costa Rica y el artículo 11 del Pacto de los Derechos Civiles y Políticos. Por un lado, la Corte de A pelaciones de Santiago desde 1991 resolvió invariablemente sobre la incompatibilidad, considerando que el conflicto normativo se resolvía en favor del tratado por su mayor jerarquía, aunque tal solución no se haya referido expresamente. Por otra parte, la Corte Suprema a partir de junio de 1991 estimó lo contrario, es decir la compatibilidad, lo que no implica necesariamente una asimilación jerárquica entre tales normas, sino ausencia de conflicto normativo.

En los casos sobre Deudas Previsionales, la Corte de A pelaciones de Santiago estuvo por resolver la incompatibilidad del artículo 12 de la Ley 17.322 y el artículo 7 № 7 del Pacto de San José de Costa Rica, otorgando preeminencia a la aplicación de este último. No así la Corte Suprema que mantuvo la posición contraria, es decir, la plena compatibilidad de estas normas.

De los fallos recaídos en los casos Lumi Videla y Uribe Tambley-Van Jurick, relacionados con la aplicación de la ley de amnistía, puede concluirse que el conflicto normativo entre el decreto ley 2191 y los tratados sobre derechos humanos, que de manera expresa o implícita prohíben aquella, se resolvió aplicando preeminentemente los tratados con base en su rango supralegal.

En la tercera etapa de Evolución Jurisprudencial, desde 1994-2005, las resoluciones recayeron esencialmente en torno a dos materias: deudas previsionales y aplicación de la ley de amnistía. En relación con los casos sobre deudas previsionales, la jurisprudencia de la Corte Suprema fue vacilante, toda vez que en algunos fallos consideró tal arresto como prohibido por los tratados internacionales, por tratarse de una prisión por deuda; y en otros casos negó la aplicación de los tratados, argumentando que no se configura la situación prevista por los tratados para impedir que se prive de la libertad a una persona, porque no existe un incumplimiento de una obligación civil. Cabe señalar que cuando la Corte Suprema identificó la incompatibilidad entre el Pacto de San José de Costa Rica y el artículo 12 de la Ley 17.322, le atribuyó mayor jerarquía al tratado que a la ley, haciendo aplicable el Pacto.

En relación con los casos sobre aplicación de la ley de amnistía, la jurisprudencia también fue vacilante. Se inicia esta etapa con el caso Carmelo Soria de 1996, en el cual la Corte Suprema reconoce igual jerarquía a los tratados que a las leyes, resol- 
viendo el conflicto normativo entre tales normas por la vía del criterio de la temporalidad. Luego, a partir de 1998 se reconoce que los tratados de derechos humanos son jerárquicamente superiores a las leyes comunes, pero jerárquicamente inferiores a las leyes de orden público, considerando como ley de orden público a la ley de amnistía. Sin embargo, recién fue en septiembre de 1998 cuando la Corte Suprema, en sentencia de casación recaída en el caso Poblete Córdova, que rompió con su sostenida tradición de aplicar la ley de amnistía y comenzó a considerar aplicable al caso lo previsto en los tratados internacionales. Claramente la decisión de los tribunales en este sentido señala el reconocimiento de una mayor jerarquía de los tratados sobre la legislación interna.

En la cuarta etapa de Evolución Jurisprudencial, desde 2005 a la fecha, en relación con la aplicación del decreto ley 2.191 puede señalarse que la tendencia de los tribunales superiores de justicia es a reconocer la "preeminencia” de la aplicación de los tratados de derechos humanos ante un conflicto normativo con la legislación interna. En casos puntuales como Lago Ranco y Urrutia Galaz se reconoce hasta el rango constitucional a los tratados de derechos humanos. Por otro lado, en casos como M uller, se hace expresa mención a la mayor jerarquía de los tratados respecto de la legislación interna, con base en lo resuelto por la Corte Interamericana sobre Derechos Humanos en el caso Almonacid A rellano vs. Chile. Todo lo anterior redundó en la no aplicación de la ley de amnistía por ser contraria al Derecho Internacional de los Derechos Humanos.

\section{BIBLIOGRAFÍA}

Alzaga Villamil, Gutiérrez Gutiérrez, Rodríguez Zapata (1997): Derecho Político Español según la Constitución de 1978 (Madrid, Editorial Centro de Estudios Ramón A reces), I.

Andrade Geywitz, Carlos (1991): Reforma de la Constitución Política de la República de Chile de 1980 (Santiago, Editorial Jurídica de Chile).

Bala guer Callejón, Francisco (1991): Fuentes del Derecho. Principios del Ordenamiento Constitucional (Madrid, Editorial Tecnos).

Benadava, Santiago (1993): Derecho Internacional Público (Santiago, Editorial Jurídica ConoSur).

Benadava, Santiago (1992): “Las Relaciones entre Derecho Internacional y Derecho Interno ante los Tribunales chilenos" en A.A.V.V. Nuevos enfoques del Derecho Internacional (Santiago, Editorial Jurídica de Chile).

Bernales Rojas, Gerardo (2003): “Los tratados internacionales, los derechos fundamentales y la jurisprudencia del período 1981-1989, bajo el régimen del art. $24^{\circ}$ transitorio de la Constitución", en Revista Ius et Praxis, 9 (1), pp. 281-327.

Bertelsen Repetto, Raúl (1996): “Rango jurídico de los tratados internacionales en el Derecho Chileno", en Revista Chilena de Derecho, 23 (2 y 3), pp. 211-222.

Bidart CAm pos, Germán (1997): Manual de la Constitución Reformada (Buenos Aires, Editorial Ediar).

Boввіо, Norberto (1987): Teoría General del Derecho (Bogotá, Editorial Temis). 
Brotons, Remiro (1985): “De los Tratados Internacionales”, en O. A lzaga (director), Comentarios da las Leyes políticas (M adrid) VII.

Carrillo Salcedo, Juan Antonio (1991): Curso de Derecho Internacional Público (Madrid, Editorial Tecnos).

CAstorina de TARquinı, María (1995): "Supremacía de la Constitución”, en A.A.V.V. Derecho Constitucional de la Reforma de 1994 (Buenos Aires, Editorial Depalma).

Cea EgañA, José Luis (2001): "El control constitucional de los actos legislativos como avance y futuro del constitucionalismo", en Revista de Derecho Público (63), pp. 428443.

Cea Egaña, José Luis (1999): El sistema constitucional de Chile. Síntesis crítica(Valdivia, Ediciones Universidad A ustral de Chile).

Cum plido Cereceda, Francisco (1991): “Historia de una Negociación para la Protección y Garantía de los Derechos Humanos", en A.A.V.A. Nuevas Dimensiones en la Protección del Individuo, (Santiago, Instituto de Estudios Internacionales Universidad de Chile).

Cumplido Cereceda, Francisco (1996): “Alcances de la Modificación del artículo 5o de la Constitución Política Chilena en Relación a los Tratados Internacionales", en Revista Chilena de Derecho, 23 (2 y 3), pp. 255-258.

Coloautm, Carlos (1999): Los Tratados Internacionales y la Constitución Nacional (Buenos Aires, Editorial La Ley).

De O тто, Ignacio (1988): Derecho Constitucional. Sistema de Fuente (Barcelona, Editorial A riel).

Diez de Velasco, Manuel (1983): Instituciones de Derecho Internacional Público (Madrid, Editorial Tecnos).

EKMEKDJIAN, M iguel Ángel (1994): “Los tratados internacionales en la reforma constitucional", en A.A.V.V. Pensamiento Jurídico (Buenos Aires, Centro de Estudiantes de la Universidad Católica A rgentina).

Fernández GonzÁlez, M iguel Ángel (2001): “La fuerza normativa de la Constitución”, en Revista de Derecho Público (63), pp. 77-102.

Flores Rodriguez, Raúl (1994): Los Tratados en la Constitución Peruana de 1979 (Lima, Ediciones Jurídicas).

García de Enterría, Eduardo (1982): Curso de Derecho Administrativo (Madrid, Editorial Civitas) I.

Garrido Falla, Fernando (1989): Tratado de Derecho Administrativo (Madrid, Instituto de Estudios Políticos) I.

Henríquez Viñas, M iriam (2003): “La Jerarquía de la Normativa de Protección Internacional en Chile" en Revista luridica, Año 3 (5), pp. 115-132.

HenríqueZ ViÑas, M iriam (2003): "Evolución de la Jurisprudencia en torno al artículo 50 inciso $2 \stackrel{0}{ }$ de la Constitución", en A nuario de la Facultad de Ciencias Jurídicas de la Universidad de Atacama, Año I (1), pp. 47-68.

Henriquez ViñAs, M iriam (2007): “Los tratados internacionales en la Constitución reformada", en Revista de Derecho Público (69), pp. 313 -323.

HIKKen, Pedro (1987): La Protección Internacional de los Derechos Humanos. Su desarrollo progresivo (Madrid, Editorial Civitas). 
HITTERS, Juan Carlos (1991): Derecho Internacional de los Derechos Humanos (Buenos Aires, Editorial Ediar) I.

Infante CAffl, María Teresa (1996): “Los Tratados en el Derecho Interno Chileno: El efecto de la Reforma Constitucional de 1989 visto por la Jurisprudencia", en Revista Chilena de Derecho, 23 (2 y 3), pp. 277-297.

Kelsen, Hans (1960): Teoría Pura del Derecho (Buenos Aires, Editorial Eudeba).

KeLSEN, Hans (1965): Principios de Derecho Internacional Público (Traducc. Hugo Caminos y Ernesto Hermida, Buenos Aires, Editorial El A teneo).

Medina Quiroga, Cecilia (1994): Constitución, Tratados y Derechos Esenciales (Santiago, Editorial Corporación de Reparación y Reconciliación).

Nogueira A lCALÁ, Humberto (1996): “Los Tratados Internacionales en el Ordenamiento Jurídico Chileno" en Revista Chilena de Derecho, 23 (2 y 3), pp. 341-380.

Nogueira A lcalá, Humberto (1997): “Los Tratados Internacionales en el Ordenamiento Jurídico Chileno", en Revista lus et Praxis, año 2 (2), pp. 9-72.

Nogueira A lcalÁ, Humberto (1995): Dignidad de la persona y Derechos Humanos: La Constitución, Tratados y la Ley de Amnistía (Valparaíso, Editorial Edeval) II.

OrREGo Vicuña, Francisco (1992): “Inmunidades Diplomáticas y Consulares y Derechos Humanos, en Nuevos Enfoques del Derecho Internacional" en A.A.V.V. Nuevos enfoques del Derecho Internacional, (Santiago, Editorial Jurídica de Chile).

Pérez Royo, Javier (2001): Las Fuentes del Derecho (M adrid, Editorial Tecnos).

Precht PizarRo, Jorge (1996): "Vino nuevo en odres viejos: Derecho Internacional convencional y Derecho Interno Chileno", en Revista Chilena de Derecho, 23 (2 y 3), pp. 146-150.

RodRIGUEZ ZaPATA, Jorge (1976): Constitución, tratados internacionales y sistemas de fuentes del derecho (Bolonia).

SILva BAscuñán, Alejandro (1997): Tratado de Derecho Constitucional (Santiago, Editorial Jurídica de Chile) I, IV.

VAnossi, Jorge (1969): Régimen Constitucional de los Tratados (Buenos Aires, Editorial El Coloquio).

VAnOSSI, Jorge; Dalla VIA, Ricardo (2000): Régimen Constitucional de los Tratados (Buenos Aires, Editorial A beledo-Perrot).

VerdRoss, Alfred (1982): Derecho Internacional Público (Madrid, Biblioteca Jurídica Aguilar).

Verdugo M ARINKovic, M ario (2003): “Notas sobre el principio de la supremacía constitucional y los decretos supremos de ejecución" en Revista de Estudios Constitucionales, Año 1 (1), pp. 387-399.

ZúNIIGA URBINA, Francisco (1997): “A mnistía ante la Jurisprudencia (derechos humanos como límite al ejercicio de la soberanía)" en Revista lus et Praxis, Año 2 (2), pp. 167-214.

\section{Jurisprudencia}

- Manuel Ugarte contra AFP Santa M aría S.A. (1991): Corte de A pelaciones de Santiago 10 junio 1991 (recurso de amparo).

- Oliverio Fullerton Sobino con A FP Summa S.A.. (1991): Corte Suprema 17 julio 1991 (apelación de recurso de amparo). 
- Manuel Ugarte con AFP Santa María S.A (1991): Corte Suprema 3 diciembre 1991 (recurso de queja).

- No se consignan (1991): Corte de A pelaciones de Santiago 5 febrero 1991 (recurso de amparo).

- No se consignan (1991): Corte de A pelaciones de Santiago 11 febrero 1991 (recurso de amparo).

- Pan World Trading Corporation con Alfredo Andonaegui Álvarez (1993): Corte Suprema 17 junio 1993 (recurso de queja).

- Lumi Videla (1994): Corte de A pelaciones de Santiago 26 septiembre 1994 (apelación).

- Osvaldo Romo Mena (1994): Corte de A pelaciones de Santiago 30 septiembre 1994 (apelación).

- Romo Mena Osvaldo (Lumi Videla Moya) (1996): Corte Suprema 30 enero 1996 (queja criminal).

- Lauriani, Fernando y Romo, Osvaldo (1998): Corte Suprema 8 septiembre 1998 (casación fondo).

- Poblete Córdova (1998): Corte Suprema 9 septiembre 1998 (casación fondo).

- Pereira Salberg, Andrés y otros (2004): Corte Suprema 11 marzo 1998 (casación fondo).

- Alejandro González Poblete; Consejo Superior Corporación Nacional Reparación con (2003): Corte Suprema 31 enero 2003 (casación fondo).

- Corporación Nacional de Reparación y Reconciliación con (2003): Corte Suprema 31 enero 2003 (casación fondo).

- Christian M ueller Maturana con (2003): Corte de A pelaciones de Santiago 25 agosto 2003 (recurso de amparo).

- Mauricio Pinto Meneses con Juez del Séptimo Juzgado del Trabajo de Santiago (2004): Corte Suprema 6 abril 2004 (apelación recurso de amparo).

- A.F.P. M agíster con Cristián A lberto M iranda Pérez, (2004): Corte de A pelaciones de Rancagua 13 agosto 2004 (recurso de amparo).

- Handel Sepúlveda Tapia; con Carlos Iván Gutiérrez Zavala Juez Letrado Titular del Primer Juzgado Civil de Temuco; Segundo Juzgado Civil de Temuco; Tercer Juzgado Civil de Temuco (2004): Corte Suprema 6 octubre 2004 (apelación recurso de amparo).

- Leonel Huerta Corrales con Eliana Silva Romero Juez del Noveno Juzgado del Trabajo de Santiago (2004): Corte Suprema 15 noviembre 2004 (apelación recurso de amparo).

- Ricardo Rioseco Reyes con Joaquín León Rivera (2004): Corte de A pelaciones de Temuco, 29 diciembre 2004 (apelación).

- González Sáez c/ INP (2001): Corte de A pelaciones de Santiago 4 mayo 2006 (apelación).

- Ramón Luis Vivanco Díaz, Adiel Monsalves Martínez, Manuel Zacarías González Vargas, José Leningrado Morales Álvarez, Arturo Koyck Fredes, Joel Guillermo Silva Oliva, Roberto Segundo Á vila Márquez, Alfredo Acevedo Pereira, Raúl Humberto Castro Caldera, Pedro Enrique Oyarzún Zamorano y Hernán Elías Chamorro Monardes con Víctor Raúl Pinto Pérez (2005): Corte de A pelaciones, 1 abril 2005 (apelación).

- Wilfredo Antilef Sanhueza con Juez Titular Primer Juzgado del Trabajo San Miguel (2005): Corte Suprema, 9 mayo 2005 (apelación recurso de amparo). 
- Hugo Iturrieta Núñez con Juez Segundo Juzgado de Letras del Trabajo de Santiago (2005): Corte de A pelaciones de Santiago 24 mayo 2005 (recurso de amparo).

- Hugo Iturrieta Núñez con Juez Segundo Juzgado de Letras del Trabajo de Santiago (2005): Corte Suprema, 30 mayo 2005 (apelación recurso de amparo).

- Christian Mueller Maturana con (2005): Corte Suprema, 1 septiembre 2005 (apelación recurso de amparo).

- Luis Vidal Riquelme Norambuena con Claudio Abdón Lecaros Carrasco; José Basilio Muñoz Pozo; Omar Antonio Mella Lillo (2005): M inistro de Fuero, 7 noviembre 2005.

- No consignado con Fernando Remigio Burgos Díaz; Sergio Antonio M edina Salazar; Isidro Custodio Durán M uñoz; José Jaime Darrigrandi Márquez (2006): Corte de A pelaciones de Santiago, 20 abril 2006.

- Fernández A cuña con Fisco (2006): Corte de A pelaciones de Santiago 21 julio 2006 (apelación).

- Contreras A burto, Luis / Ruiz Bunger, Freddy; Saavedra Loyola, Juan; Cobos Manríquez, Jorge; Guimpert Corvalán, Daniel; Muñoz Gamboa, M anuel; Palma Ramírez, César; Sáez Mardones, A lejandro (2006): Corte de A pelaciones de Santiago 31 julio 2006 (apelación).

- Julio Pérez Fuenzalida con Juzgados de Letras del Trabajo de Santiago (2006): Corte de A pelaciones de Santiago, 11 octubre 2006 (recurso de amparo).

- Julio Pérez Fuenzalida con Juzgados de Letras del Trabajo de Santiago (2006): Corte Suprema, 16 octubre 2006 (apelación recurso de amparo).

- Estado de Chile; M iriam Luz Ancacura Pafián; María Ester Hernández Martínez; con Sergio Héctor Rivera Bozzo (2006): Corte de A pelaciones de Santiago 8 noviembre 2006 (apelación).

- No se consigna con Víctor Raúl Pinto Pérez, (2007): Corte Suprema 13 marzo 2007 (casación fondo).

- Rudolph Muller Muller; Sonia Ida M aría Muller Silva con Fisco de Chile (2007): Corte de A pelaciones de Santiago 23 marzo 2007 (apelación).

- M ario Urrutia Villa con Freddy Enrique Ruiz Bunger; Juan Francisco Saavedra Loyola; César Luis Palma Ramírez; Otto Silvio Trujillo Miranda; Eduardo Enrique Cartagena Maldonado (2007): Corte de A pelaciones de Santiago 2 Agosto 2007 (apelación).

- Benito M illalén Sandoval con A ugusto Pinochet Ugarte; Germán Víctor Fagalde Osorio; M ario Hernán Fagalde Osorio; Enrique Ferrier Valeze (2007): Corte de A pelaciones de Santiago 3 agosto 2007 (apelación). 